\title{
EL ALFAR DE RABATÚN (JEREZ DE LA FRONTERA, CÁDIZ) Y LA PRODUCCIÓN DE ÁNFORAS Y CERÁMICA COMÚN EN LA CAMPIÑA DEL GUADALETE EN ÉPOCA ALTOIMPERIAL ROMANA
}

\author{
THE RABATÚN KILN (JEREZ DE LA FRONTERA, CÁDIZ) AND THE \\ PRODUCTION OF AMPHORAE AND COMMON POTTERY IN THE \\ GUADALETE COUNTRYSIDE DURING OF EARLY ROMAN EMPIRE
}

\author{
ENRIQUE GARCÍA VARGAS* \\ ESTER LÓPEZ ROSENDO**
}

\begin{abstract}
Resumen: La excavación del año 2003 en el yacimiento de Los Villares-Montealto, permitió excavar en extensión una amplia zona artesanal de época altoimperial romana. Se trata de un alfar que era conocido en la bibliografía como Rabatún, por ser este el nombre que recibe el pago situado en la falda del cerro en la ladera del Cerro de Montealto, pero del que no se conocían por hallazgos esporádicos más que producciones de ánforas Beltrán II B. Los trabajos efectuados en el yacimiento han permitido detectar estructuras correspondientes a dos fases distintas de producción en las que se fabricaron ánforas Dressel 9/10; Oberaden 83, Dressel 10B (primera fase) y Beltrán IIB (segunda fase), además de cerámicas comunes. La primera fase se fecha sobre la base de las cerámicas finas de mesa en la primera mitad del siglo I d. C., mientras que la segunda, con los mismos elementos, ocuparía los años finales del siglo I d. C. y la primera mitad del siglo II d. C. Es posible que el alfar siguiese activo en otro lugar de la finca Los Villares en la segunda mitad del siglo II d. C. produciendo Beltrán II B. evolucionadas y Puerto Real 1.

Palabras clave: Alfar romano, ánforas, cerámica común, ladrillos, tégulas
\end{abstract}

\section{INTRODUCCIÓN}

En 1936 ingresaron en el Museo Arqueológico de Jerez de la Frontera dos ánforas romanas completas donadas por el marqués de Campo Real como procedentes del Pago de Rabatún, concretamente de las laderas

\footnotetext{
* Universidad de Sevilla.

** Universidad de Cádiz..
}

\begin{abstract}
The digging season carried out in 2003 in the site of Los Villares-Montealto allowed for the open area excavation of a substantial manufacturing quarter dating to the Early Roman Empire. It was the pottery workshop known in the literature as Rabatún, after the estate on the hillside of Cerro de Montealto, of which only amphorae of the Beltrán II B type were previously known, due to the sporadic nature of finds. The excavation of the site uncovered features corresponding to two production phases, producing amphorae of the Dressel 9/10, Oberaden 83 and Dressel 10B types (first phase) and Beltrán IIB type (second phase), along with other coarse wares. According to the fine table wares found, the first phase must date to the first half of the 1st Century A. D., whereas the second would fall in the late 1st and the first half of the 2nd century A. D. It is possible that the workshop remained active in a different location within the estate of Los Villares in the second half of the 2nd century A. D., engaged in the production of amphorae of the evolved Beltrán II B and Puerto Real 1 types.

Key words: Roman pottery workshop, amphorae, coarse wares, bricks, tegulae.
\end{abstract}

del cerro de "Montealto". Una de ellas, en perfecto estado de conservación, fue publicada primero por M. Beltrán Lloris en su libro pionero sobre las ánforas romanas en España (Beltrán 1970) y luego por uno de nosotros (García Vargas, 1998, p. 420 lám. 199, 406, lám. 2) en un trabajo monográfico sobre la producción de ánforas romanas en el área gaditana. En ambos casos, la asignación tipológica de la pieza se hacía en el seno de las producciones que se han dado en llamar Beltrán IIB, cuyos 
límites cronológicos generales se sitúan entre la primera mitad del siglo I y finales del II d. C., con indicación en el segundo caso (García Vargas 1998: 188) de que el ánfora en cuestión procedía de un centro de producción cerámica, de una figlina o alfar situado en el área inmediata del núcleo urbano actual de Jerez de la Frontera.

Este alfar fue incluido por L. Lagóstena Barrios y D. Bernal Casasola (2004: 60) en su catálogo de los talleres cerámicos de la provincia de Cádiz con el topónimo Rabatún-Bodegas Croft, señalando que se ubicaba en el km. 637 de la Nacional IV y atribuyéndole igualmente la producción de ánforas de la forma Beltrán IIB, para lo cual remitían a las ánforas del Museo de Jerez recogidas en la escasa bibliografía anterior. Dichas ánforas Beltrán IIB eran, en efecto, los únicos testimonios que permitían caracterizar morfológica (y cronológicamente) las producciones de Rabatún hasta que a comienzos del año 2004 las obras de urbanización del área, derivadas del proyecto de construcción de una promoción de viviendas, obligaron a la delimitación y excavación entre febrero de 2004 y julio de 2005 del yacimiento de Los Villares-Montealto, situado en el interior de una extensa parcela de $210.557 \mathrm{~m}^{2}$ del cual el alfar romano de Rabatún no constituye sino un sector, ubicado en la ladera meridional del llamado Cerro de Montealto. Se pudo entonces ampliar la información estratigráfica y cronotipológica de la figlina de Rabatún, gracias a la excavación en la citada ladera de diversas estructuras altoimperiales destinadas a la elaboración de ánforas, cerámica común y materiales de construcción que correspondían a dos fases cronológicas claramente diferenciadas; la primera de ellas, se fecha entre el cambio de Era y mediados del siglo I d. C. y la segunda entre fines del siglo I y mediados del II d. C., momento en el que el área artesanal es amortizada por una necrópolis, aunque como se verá más adelante, es posible que la producción cerámica se trasladara a otro sector del alfar, que continuaría en actividad hasta época antonina tardía o severiana.

Serán las estructuras correspondientes al alfar romano de Rabatún y las producciones cerámicas en él elaboradas las que centrarán nuestro interés en este trabajo, lo que no nos exime, desde luego, de realizar una somera descripción del yacimiento en el que se localizan (cf. López Rosendo 2007).

\section{EL YACIMIENTO DE LOS VILLARES-MONTEALTO}

El alfar de Rabatún constituye, como se ha indicado, un sector, el nororiental, de un yacimiento arqueológico más amplio que recibe la denominación de
"Los Villares-Montealto". Localizado al noroeste de la ciudad de Jerez (Fig. 1), entre las bodegas Garvey y las instalaciones de la Confederación Hidrográfica del Guadalquivir, se accede a él a la altura de la intersección entre la Nacional IV y la carretera a Trebujena y Mesas de Asta. En el yacimiento se distinguen dos zonas diferentes, una baja al SO denominada "Los Villares" y un pequeño cerro al NE con una cota de $90 \mathrm{~m}$. s.n.m. llamado "cerro de Montealto", en cuya ladera meridional, conocida como "Pago de Rabatún", se encuentra el alfar. El topónimo Rabatún parece derivar del árabe ribat-al-Yun y haría referencia a la existencia en las cercanías de un puesto de vigilancia y defensa medieval, asociado a un camino de acceso a la ciudad islámica de Xeret.

El cerro de Montealto constituye el punto topográfico de mayor altura en la población actual de Jerez, lo que justifica que sobre él se construyera el pasado siglo los nuevos depósitos de agua que abastecen a la ciudad. A nivel geológico, su sustrato está constituido por margas terciarias, conformadas en el Mioceno Superior, y conocidas tradicionalmente como "albarizas". De color blanquecino y naturaleza muy plástica, presentan una gran capacidad para retener la humedad. En la zona más baja de la ladera oeste del cerro es frecuente la surgencia de humedales que son reductos de antiguos arroyos hoy desecados. Estas vaguadas vertían hacia la paleodesembocadura del río Guadalete (Fig. 2), posiblemente a la altura de las antiguas playas de San Telmo, a través de la cañada o Arroyo de la Loba y se inundaban a modo de caños mareales. Los trabajos arqueológicos han detectado, en efecto, entre las laderas del cerro y la zona de los Villares una vaguada natural que atraviesa de Noroeste a Sureste el yacimiento y que resulta ser el cauce de un antiguo arroyo que arrastraba fango y restos de cerámicas romanas muy rodadas (fundamentalmente ánforas y dolia) procedentes del desplazamiento de los vertidos cerámicos del alfar de Rabatún hacia la zona baja de ladera de Montealto. Es precisamente este elemento natural del paisaje antiguo, fosilizado como una vaguada, el que divide las dos áreas del yacimiento que denominamos "Los Villares" y "Pago de Rabatún-Montealto" (supra).

La división natural es también cronológica y cultural, pues la zona de "Los Villares" corresponde a una llanura en la que se documentan espacios de habitación de épocas calcolítica, protohistórica y tardorromana, destacando nueve "fondos de cabaña" y diversos "silos" fechados en el siglo VI a. C. que parecen constituir una "aldea" de época Orientalizante tardía (sobre la que puede verse: López Rosendo 2007: 13-14), así como estructuras similares fechadas mil doscientos 


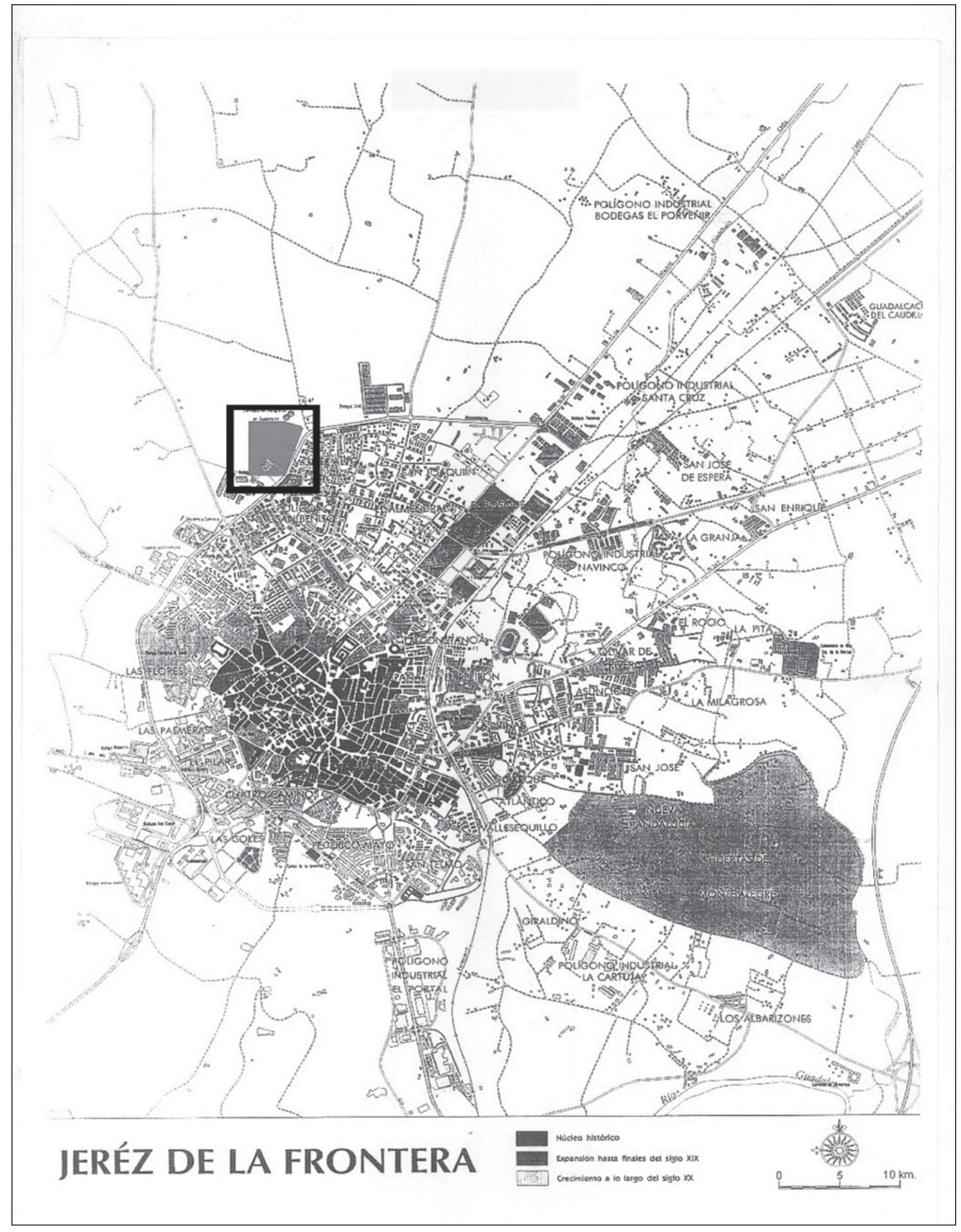

Figura1. Ubicación del yacimiento de Los Villares-Montealto. 


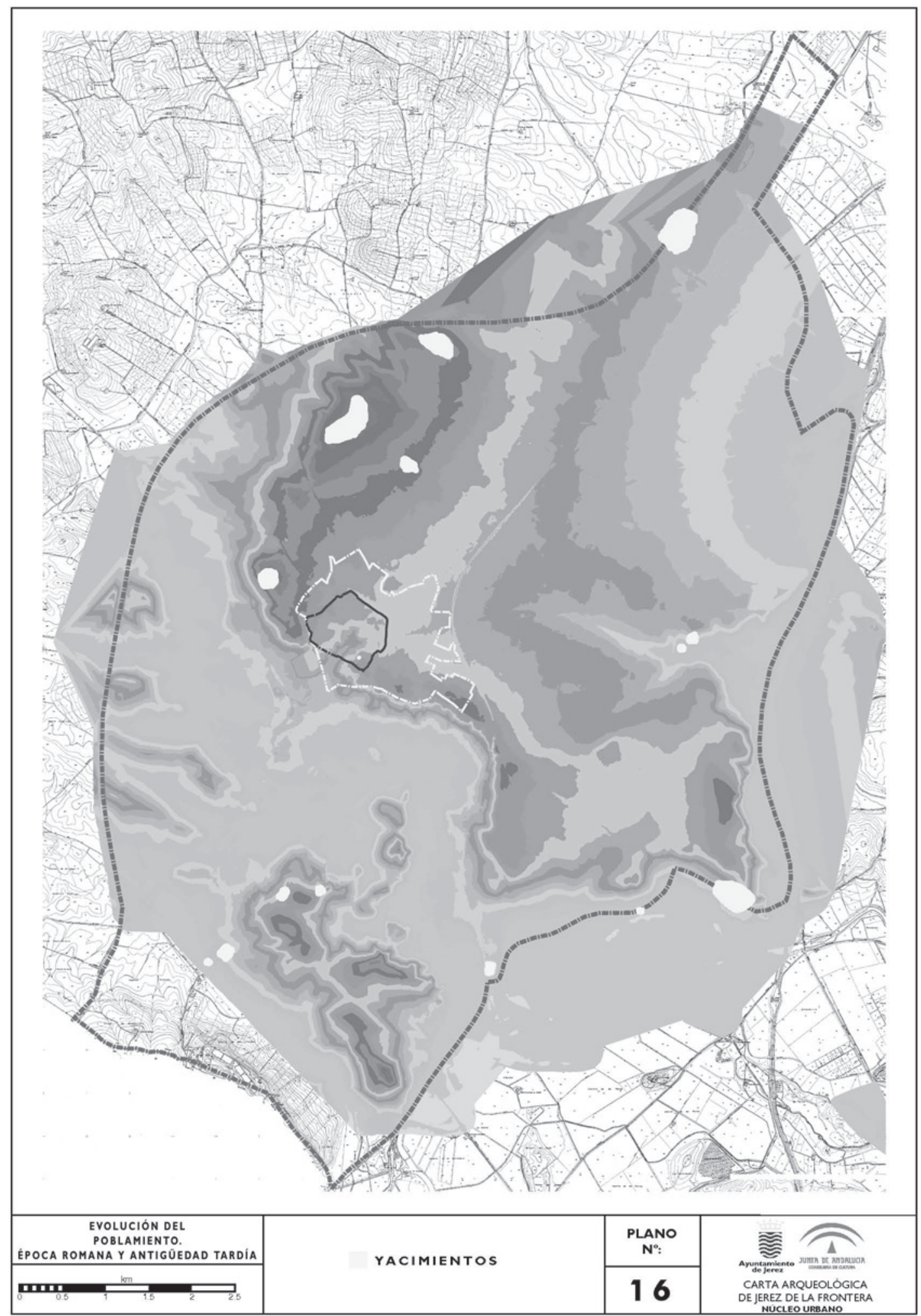

Figura 2. Reconstrucción paleotopográfica del entorno de Jerez de la Frontera en época romana (según González Rodríguez et alii 2008). 


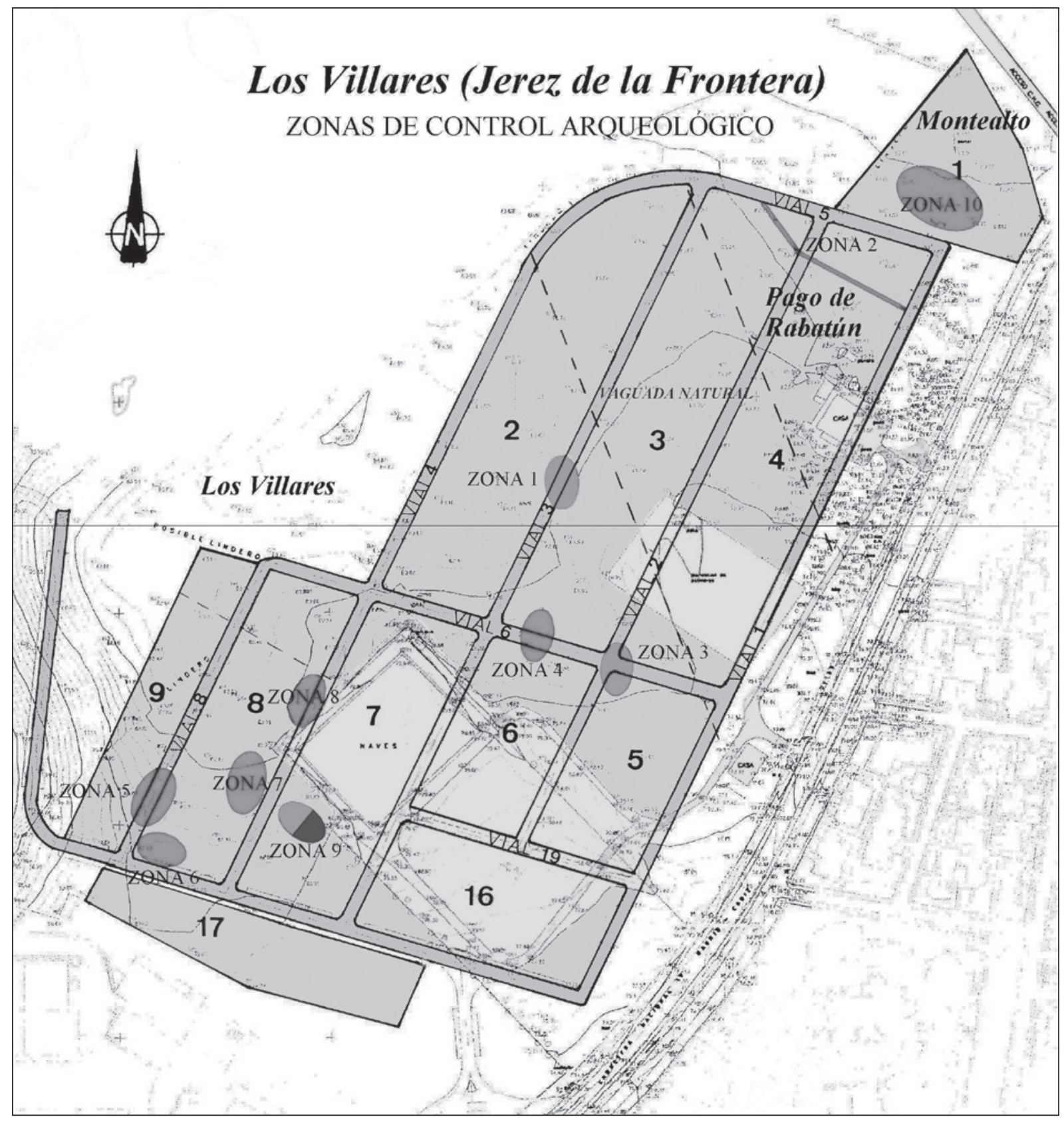

Figura 3. Los Villares-Montealto: zonas de control arqueológico y microtoponimia.

años más tarde, en el siglo VI d. C. En la ladera del cerro de Montealto, donde se sitúa el pago de Rabatún, se constatan, por el contrario, estructuras de tipo "industrial" correspondientes a una antigua alfarería romana cuya presentación es el objeto principal de este trabajo. En ella se documenta igualmente una extensa necrópolis superpuesta estratigráficamente al taller alfarero (cf. López Rosendo 2007).

\section{EL ALFAR ROMANO DE RABATÚN}

El alfar de Rabatún se localiza de lleno en el cerro de Montealto que alcanza su cota máxima a unos 90 m s.n.m. La extensión conocida del alfar es hasta el momento de $1500 \mathrm{~m}^{2}$ excavados en la Parcela $1 \mathrm{de}$ la urbanización proyectada (Zona 10: Fig. 3) y sus estructuras arqueológicas más antiguas corresponden a 


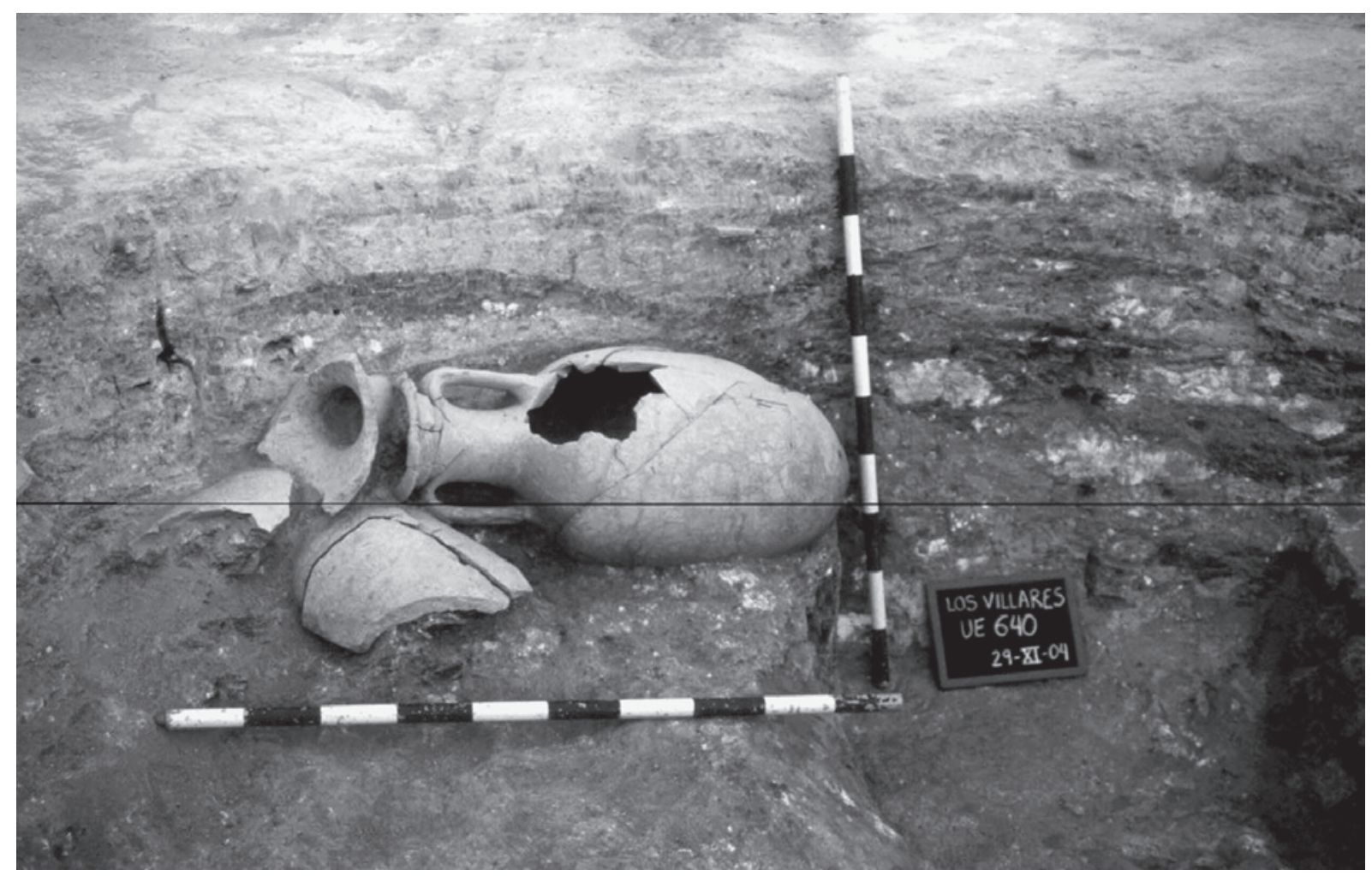

Figura 4. Primera fase de producción: relleno de la cubeta UE 640.

depósitos documentados en la ladera sur a una cota de 83 m s.n.m., cota que se relaciona con la plataforma más alta excavada hasta el presente. Las estructuras más destacadas son tres fosas (U.E. 640, 650 y 660) de las que al menos dos se excavaron posiblemente para la extracción de arcilla y que posteriormente fueron amortizadas con los desechos de la primera época de producción conocida del alfar (testares). A este momento pertenece probablemente un pequeño horno detectado en la misma área que, por sus pequeñas dimensiones debe relacionarse con la producción de la cerámica común documentada en los rellenos que colmaban la fosa U.E. 650.

En una zona baja de la ladera de Montealto, a una cota de 81 '5 m s.n.m., se documentaron estructuras correspondientes a un momento más avanzado en la producción de este alfar, ya que el tipo cerámico que predomina en ellas es el ánfora Beltrán IIB, acompañado esta vez por sigillatas hispánicas. Las Beltrán IIB aparecen en superficie por toda la extensión del yacimiento de Los Villares/Rabatún, debiendo corresponder a los últimos testares o vertederos acumulados antes del abandono del alfar. A esta fase corresponden las ánforas depositadas en 1936 en el Museo de Jerez.

\subsection{Las estructuras de la fase I}

\subsubsection{Cubetas de extracción de arcilla}

La estructura de mayores dimensiones documentada hasta ahora en el alfar de Rabatún se localizó en la zona central de la Parcela 1, en la plataforma de cota superior que baja de la ladera sur de la Confederación Hidrográfica del Guadalquivir. A nivel estratigráfico se ha identificado como U.E. 640. Se trata de una gran cubeta (Figs.4 y 5) de extracción de arcilla o barrero, de sección circular, excavada en la marga natural y de unos 4 $\mathrm{m}$ de diámetro. En el interior de la fosa y ya desde la superficie afloraban numerosos restos de ánforas y tegulae romanas insertas en una matriz de tierra pardo-grisácea. No existían indicios de combustión, o de tierra roja por lo que se descartó desde el primer momento que se tratase de un horno de fabricación anfórica.

La profundidad total de la fosa era de 1,90 m, y en ella se alternaban depósitos de tierra de color pardo grisáceo con lechadas de marga blanca (Fig. 5) que definen diversas UU.EEs depositadas en un mismo momento o en fechas muy cercanas entre sí. Por lo general las lechadas de marga eran estériles a nivel arqueológico y 


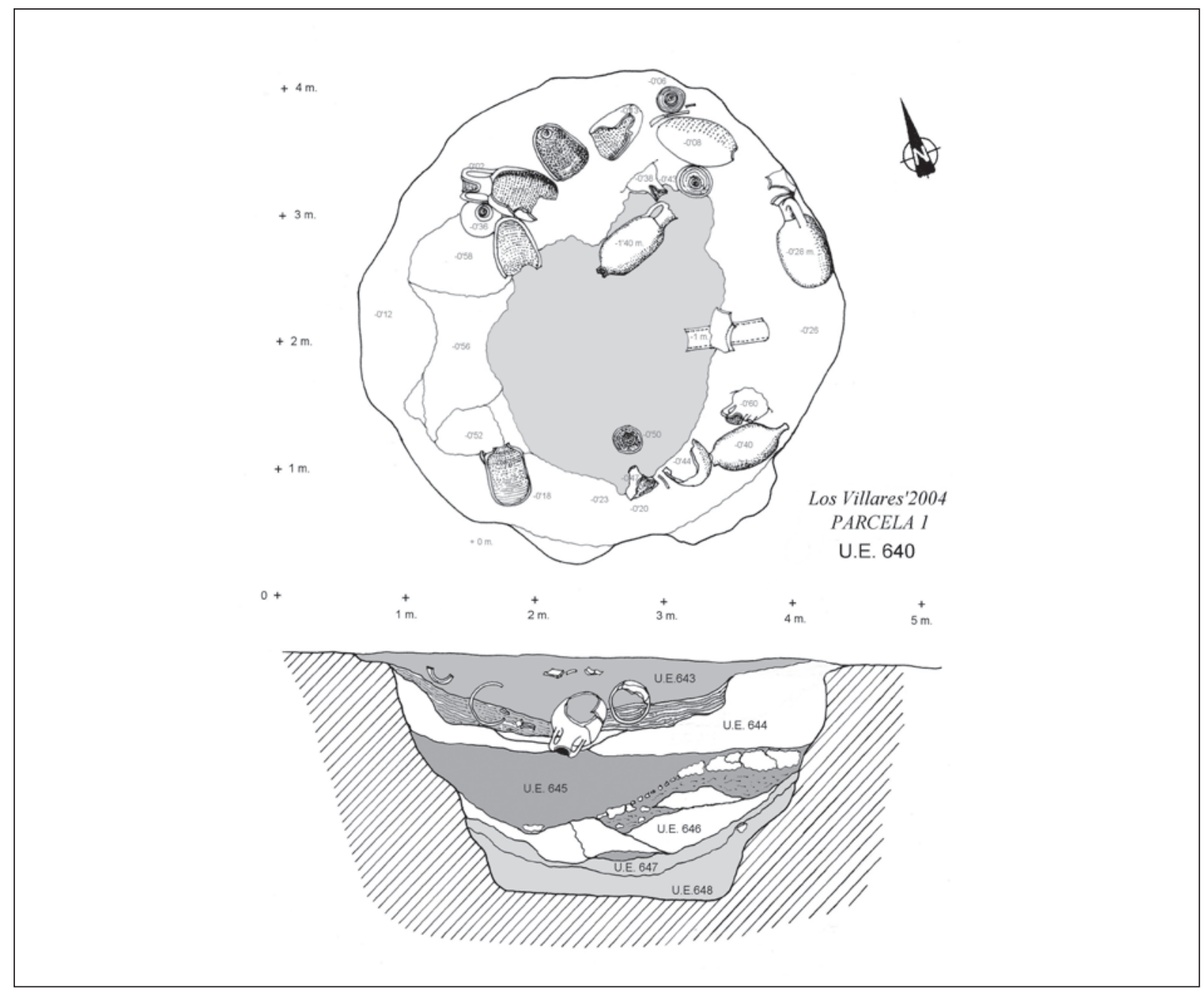

Figura 5. Rabatún. Fase I: cubeta UE. 640. Planta y perfil.

la mayor concentración de restos cerámicos se depositaba en los estratos de tierra. No sólo aparecían las ánforas del tipo Dressel 7/11, algunas semicompletas, sino que también recuperamos algunos dolia, lucernas, vasos de Paredes Finas decorados a la barbotina y numerosos elementos constructivos como tegulae, ímbrices o ladrillos, así como restos de fauna que confirman el carácter de fosa de desechos del depósito tras haber funcionado como cantera para la extracción de arcilla (la marga natural del terreno).

La U.E. 660 es una segunda fosa asociada a la actividad del alfar y localizada a unos 15 metros al Suroeste de la U.E. 640. Se trata de un depósito de restos de ánforas fragmentados insertos una matriz de tierra parda, con un diámetro en la superficie de l' $50 \mathrm{~m}$ (Norte-Sur) por 1 '90 m (Este-Oeste), y una profundidad máxima de 0’37 m, aunque ha perdido gran parte de su estructura original. Los materiales que contenía estaban fracturados e incompletos, por lo que podemos interpretar que en un principio también pudo originarse como una pequeña cantera de extracción de marga, amortizada posteriormente como depósito de desechos. En su contenido se contabilizan 15 bordes de ánforas Dressel 7/11, dolia y jarras de cerámica común.

\subsubsection{Zanja ¿para canalización?}

La U.E. 650 constituye una zanja alargada y recta que posiblemente se excavó en época romana a modo de canalización, tal vez relacionada con el indispensable aprovisionamiento de agua que necesitaban los centros de producción alfarera. Se desarrolla a unos 10 $\mathrm{m}$ al nordeste de la UE. 640 y presenta una longitud 


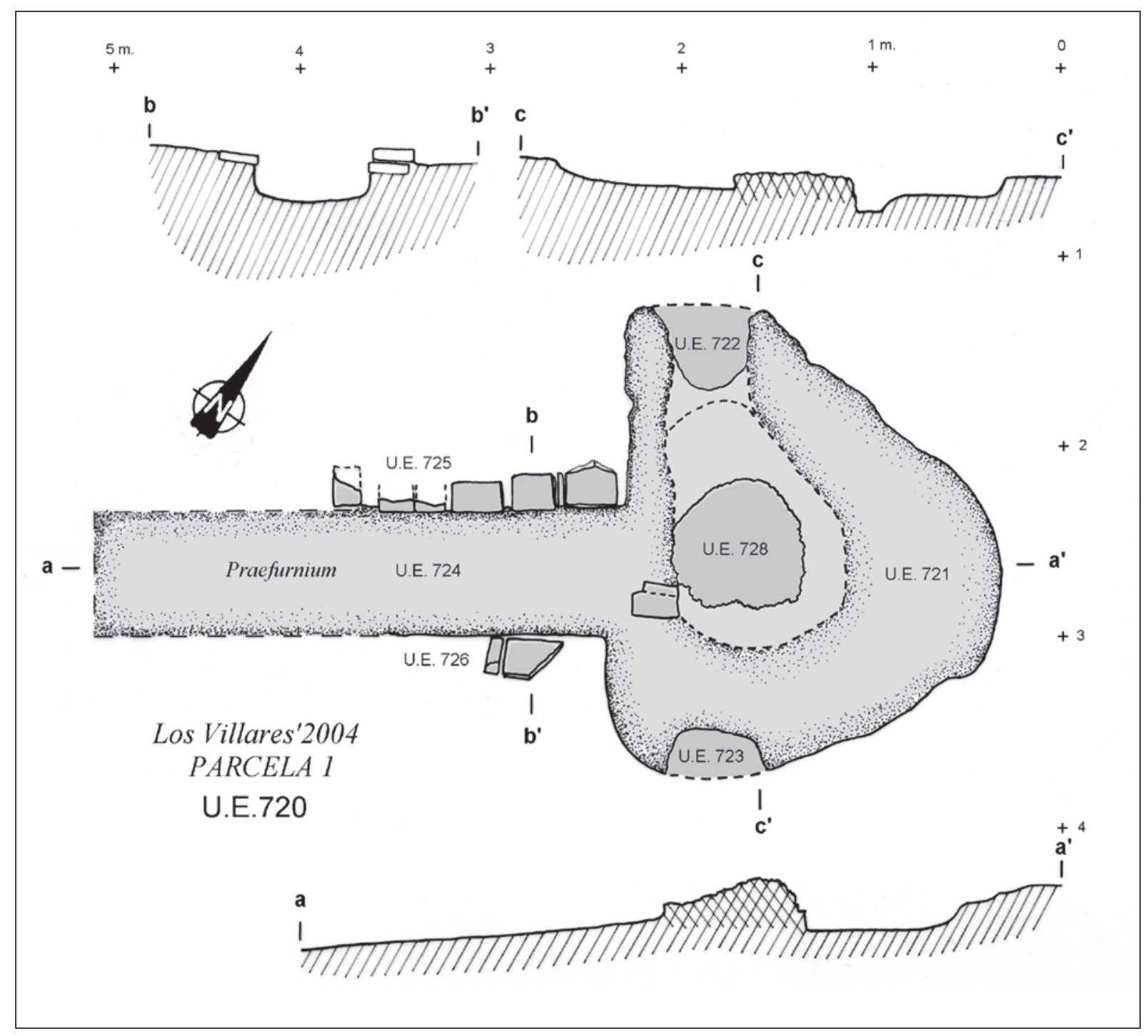

Figura 6. Rabatún. Fase I. Horno cerámico

máxima de $17 \mathrm{~m}$ conservados, aunque, en origen, pudo ser más larga. En su trayectoria, se dirige en perpendicular hacia la carretera N-IV donde apenas contiene material arqueológico en su composición. Presenta una cabecera redondeada, donde alcanza mayor anchura, cerca de $1 \mathrm{~m}$, para ir reduciendo su anchura a medida progresa en línea recta hacia el SE. La anchura alcanzada en su punto medio es de $0,55 \mathrm{~m}$ y en el extremo final localizado de $0,35 \mathrm{~m}$. El dibujo de la sección longitudinal presenta una mayor profundidad en la cabecera, donde adquiere forma redondeada y alcanza una cota de profundidad de 0,40 m para ir ascendiendo suavemente hacia el final, donde apenas alcanza una profundidad de $0,20 \mathrm{~m}$.
Esta zanja presenta en la zona centro occidental un gran depósito de cerámicas y huesos de época romana altoimperial. La mayor concentración de material arqueológico se acumula a 3'40 $\mathrm{m}$ de la cabecera y se desarrolla a lo largo de los tres metros siguientes. Entre los restos documentados destaca una gran cantidad de restos anfóricos (del tipo exclusivo de Dressel 7/11) y cerámica común romana, aunque también se han recuperado algunos fragmentos de lucernas y sigillatas. Junto a los restos cerámicos también se documentan cinco clavos de hierro y numerosos huesos de animales, sobre todo mandíbulas de bóvidos y de suidos. El depósito analizado en conjunto parece de procedencia doméstica, aunque la documentación de 70 bordes de 


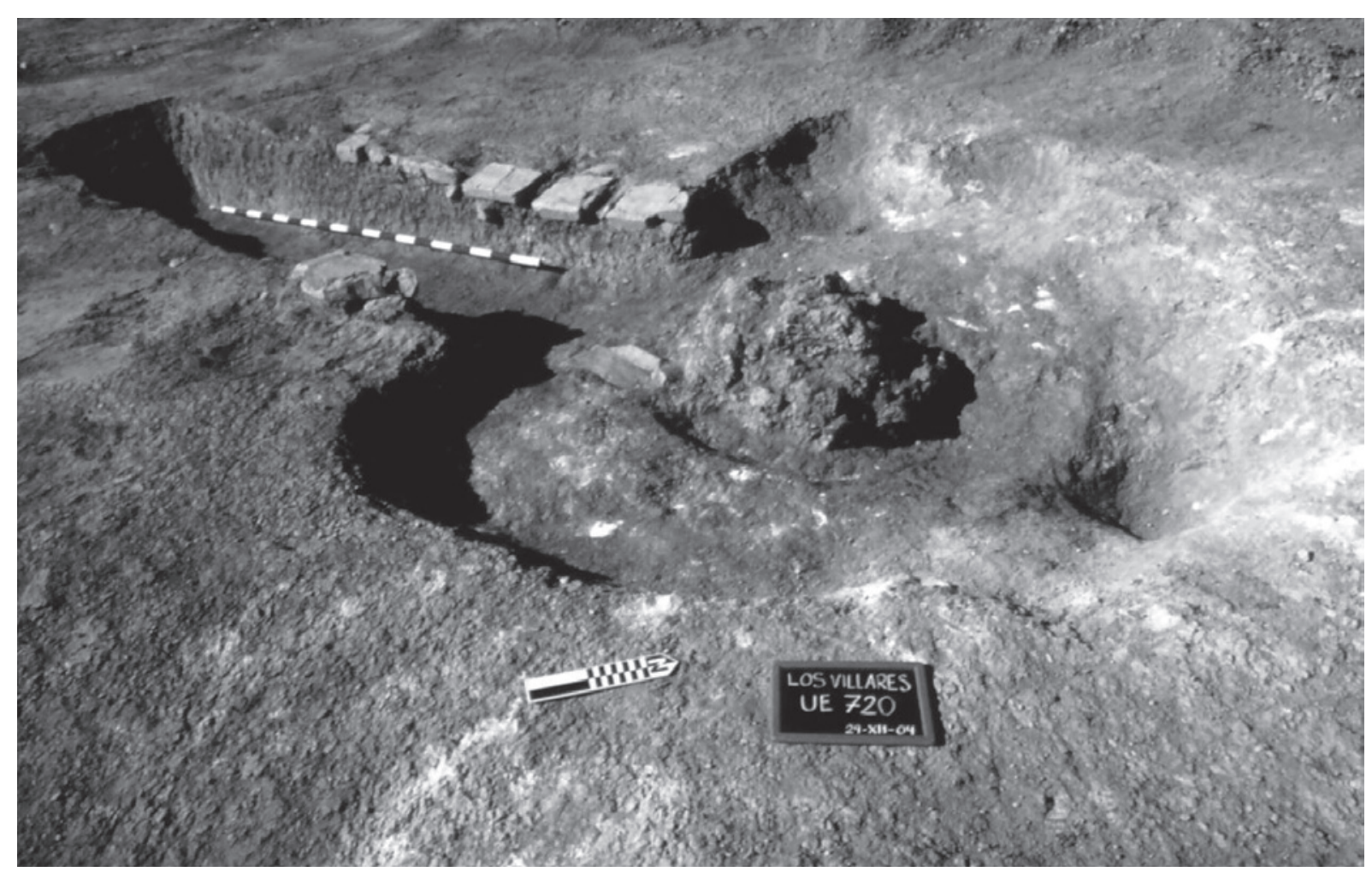

Figura 7. Primera fase de producción: horno cerámico.

ánforas romanas indica que su relleno se hizo no sólo con desechos de tipo habitacional, sino también con descartes de la producción industrial anfórica relacionada con el posible asentamiento romano en las proximidades de Montealto.

\subsubsection{Horno de producción alfarera}

Hasta el momento sólo se ha documentado un pequeño horno alfarero (Fig. 6 y 7), muy arrasado, que por sus dimensiones pudiera servir para la fabricación de pequeños recipientes de cerámica común destinadas para usos domésticos y terracotas, empleadas en algunos rituales funerarios. Por el contrario, no se han detectado los hornos industriales para la fabricación de las ánforas y los dolia, por lo que es de esperar la aparición de hornos de mayor envergadura en los alrededores de las actuales instalaciones de la Confederación Hidrográftca del Guadalquivir

El horno se localiza en el extremo oeste del alfar. Se trata de una pequeña estructura muy arrasada que sólo conserva la parte inferior de la cámara de combustión y las hileras inferiores de los ladrillos que constituían el corredor de alimentación del horno o prefurnium. Fue detectada al desbrozar la Parcela 1 como un círculo de adobe de color rojo muy intenso que definía un espacio de combustión. La estructura presenta una cámara casi circular de unos $2 \mathrm{~m}$ de diámetro (U.E. 721), orientada hacia el nordeste, con un derrumbe de adobes rojos quemados en el centro de 0'80 m de diámetro (U.E. 728) y pilastras semicirculares adosadas a las paredes laterales de la parte más ancha de la cámara (U.E. 722 y U.E. 723), posiblemente para sustentar un arco de apoyo de la parrilla al que corresponderían los restos del derrumbe central de ladrillos (tipo IC de Cuomo di Caprio: 2007, cf. Coll Conesa 2008: fig. 2). A partir de este punto de arranque del arco, la cámara dejaba paso a un pequeño corredor central o praefurnium (U.E. 724) que conservaba $2,7 \mathrm{~m}$ de longitud por una anchura de $0,65 \mathrm{~m}$, en rampa debido a la ladera natural del terreno donde está excavado. Conserva parte de las primeras hileras de ladrillos que constituían el alzado de sus paredes, una hilera con seis ladrillos puestos en plano en la vertiente oeste (U.E. 725) y dos hileras con dos ladrillos en la vertiente este del corredor (U.E. 726). La cámara estaba igualmente excavada en la marga natural del terreno y conservaba una altura de $0,24 \mathrm{~m}$, mientras 


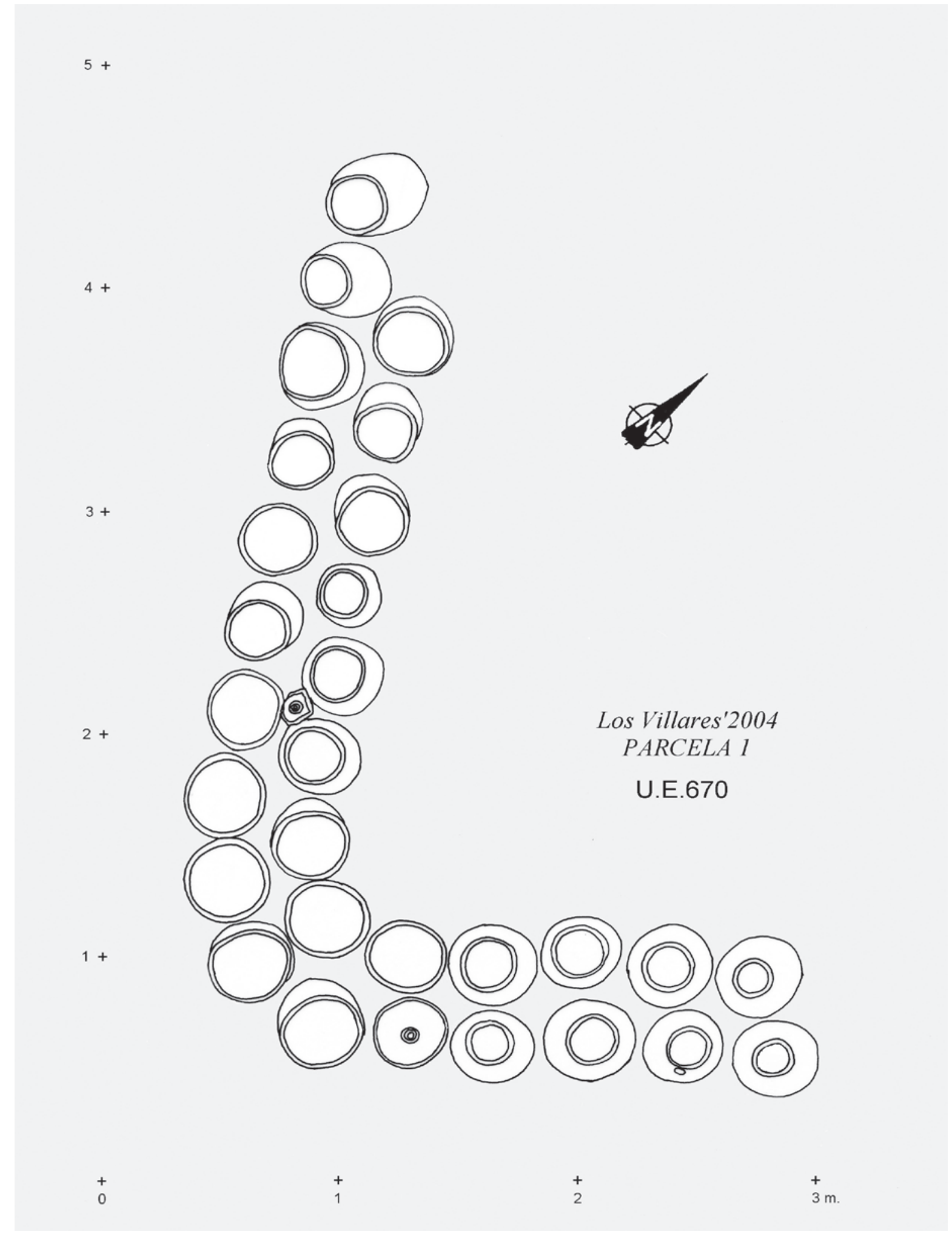

Figura 8. Rabatún. Fase II. Alineación de ánforas 


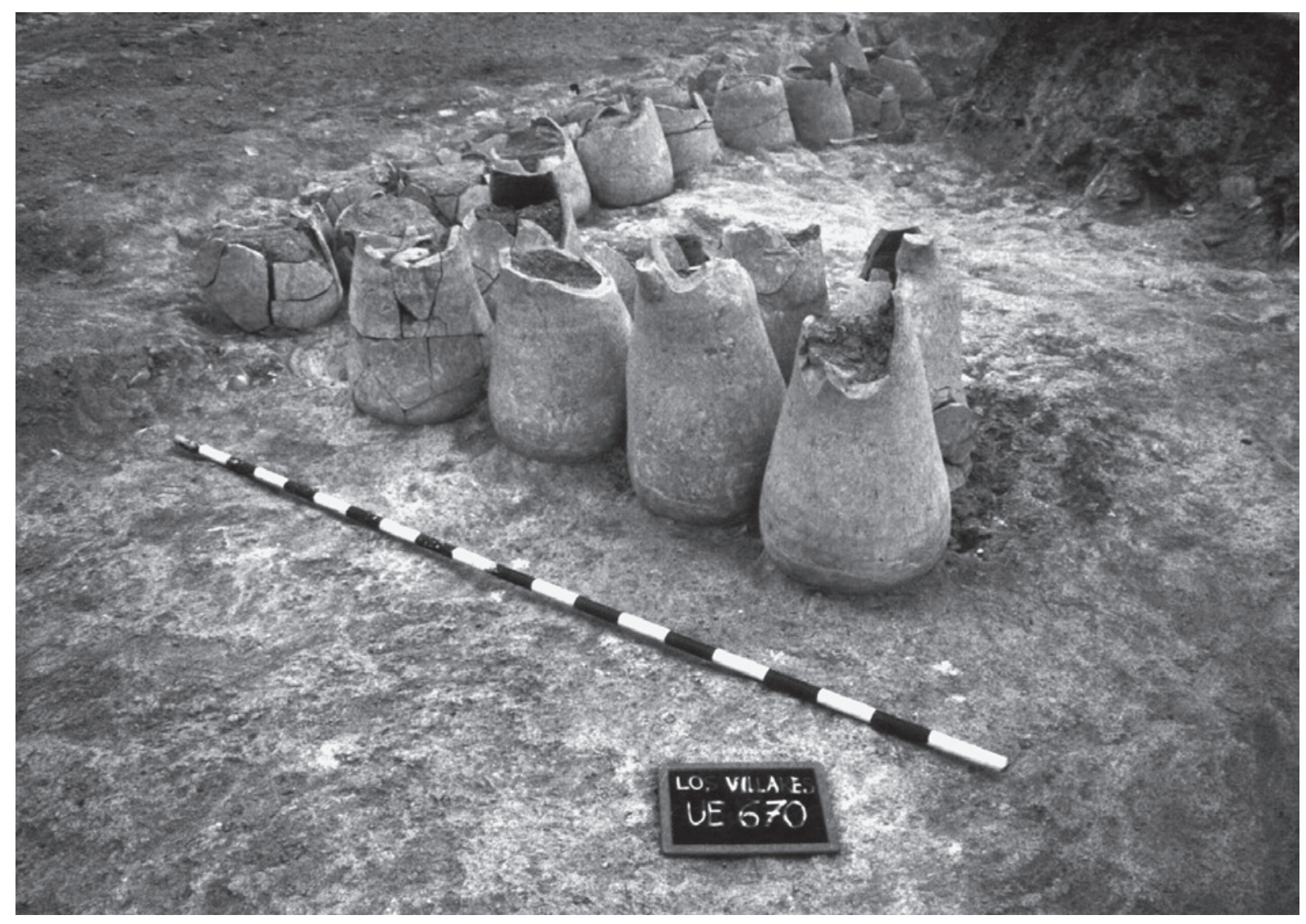

Figura 9. Segunda fase de producción: alineación de ánforas.

que el corredor, que comienza a una cota de $0,20 \mathrm{~m}$, alcanza una profundidad máxima de $0,32 \mathrm{~m}$ en el extremo suroeste. Todo el recinto, tanto la cámara como el praefurnium, estaba cubierto de arcilla roja (U.E. 727) producto de la combustión que incluso había afectado al fondo de la fosa excavada en la marga.

\subsection{Las estructuras de la fase II}

\subsubsection{Alineación de ánforas}

La U.E. 670 se ha definido como una alineamiento de ánforas embutidas en la marga natural del terreno (Figs. 8 y 9). Las 29 ánforas halladas aparecen en dos filas paralelas y se disponen en línea recta con un quiebro de $80^{\circ}$, amoldándose posiblemente a una superestructura que no se conserva. Se encuentran colocadas de pie in situ, aunque desmochadas por la parte superior debido al arrasamiento superior de la ladera por las tareas agrícolas practicadas en el terreno. Presenta unas dimensiones de 2,60 $\mathrm{m}$ de largo por 0,75 $\mathrm{m}$ de ancho en el tramo nordeste-suroeste y de 3 ' 90 m en el eje surestenoroeste. Las ánforas que se conservan más completas llegan a superar los 0,60 $\mathrm{m}$ de altura sobre la base de las margas. Es posible que sobre esta base se colocara una segunda hilera de ánforas por encima y en una segunda altura, pues entre las ánforas es frecuente encontrar restos de pivotes encastrados correspondientes a una segunda fila superpuesta que no se conserva posiblemente por haber sido destruidas por los arados modernos. Todas las ánforas corresponden a un mismo tipo (Beltrán IIB), que se fecha a partir de la segunda mitad del siglo I y sobre todo a lo largo del siglo II d.C., y que posiblemente se fabricaran en serie en este alfar en un momento posterior a la formación de los depósitos de media ladera UU.EE. 640, 650 y 660. En la provincia de Cádiz también se conoce una estructura anfórica de semejantes características a la aquí descrita que corresponde al alfar de Villanueva en Puerto Real, publicado por Jiménez Cisneros en 1971, presentando las alineaciones de ánforas espacios angulares, en dos hileras de ánforas 
paralelas colocadas en vertical, y en algunos casos apilados hasta en tres alturas. En este caso, se sugiere una función de las ánforas colocadas en líneas que se cortan entre sí, como muros delimitadores de espacios del taller (Lagóstena y Bernal 2004: 103).

En el caso de Rabatún, el depósito de ánforas pudo cumplir un cometido similar, pero son posibles otras interpretaciones alternativas, debido al hecho de que se ubica en la parte de topografía más baja de la ladera donde se localiza la Parcela 1 . Al fondo de esta pendiente se documenta una vaguada de tierra fangosa muy apelmazada, confirmada por las fotografías aéreas, que nos induce a pensar que en la Antigüedad debió constituir un pequeño riachuelo hoy desecado. De hecho numerosos bordes de ánforas de este tipo se han localizado a lo largo de todo el solar de Los Villares, sobre todo integrados en estos depósitos de vaguadas, arrastrados posiblemente desde la zona del alfar de la Parcela. Esta ubicación haría posible una finalidad del "muro" como dique de contención similar al documentado recientemente en las excavaciones que se están llevando a cabo en el Callejón del Moro de San Roque (Blánquez et alii 2004), posiblemente la antigua zona portuaria relacionada con la ciudad romana de Carteia, a modo de "diques para evitar las inundaciones fluviales”. Las ánforas del tipo Beltrán IIB se localizaron también en tres hileras paralelas, colocadas en vertical y embutidas en la arena natural del terreno. La interpretación dada a esta estructura es la de una especie de muro de contención de tierra, fabricado con las propias ánforas del alfar que servirían para dar consistencia al substrato natural de arena, cerca del nivel freático. Esta interpretación puede explicar también la estructura anfórica documentado en Rabatún ya que, al levantarlas de su posición original, presentaban todas el fondo sin pivote, lo cual invalidaría su funcionalidad como envases de comercio.

\subsubsection{Testar o vertedero}

La U.E. 700 es considerada como parte del testar, o escombrera del alfar de Rabatún. Se trata de un depósito de ladera muy potente y de gran extensión que se desarrolla inclinado hacia la vertiente sur de la colina que baja desde la Confederación Hidrográfica en Montealto hasta el Pago de Rabatún. Se deposita por debajo del área de las UU.EE. 640, 650 y 660 y cubre por completo la U.E. 670. Constituye un estrato muy denso repleto de fragmentos de ánforas, fundamentalmente del tipo Beltrán IIB, entre las que también se encontró una llave de hierro romana. Sobre este testar se construyeron las tumbas que amortizan el espacio del alfar, una vez que dejó de funcionar como tal. Por posición estratigráfica debe considerase el vertedero de las últimas ánforas producidas en el alfar de Rabatún. Debieron hallarse a la vista en época tardoantigua, ya que no sólo rellenan algunos de los silos tardorromanos de la Parcela 8 del yacimiento de los Villares, sino que se utilizaron también para hacer algunas cimentaciones de construcciones posteriores. La fecha del testar o testares de ánforas Beltrán IIB viene proporcionada por las mismas ánforas (mitad del siglo I-siglo II d.C.) y matizadas por las sigillatas hispánicas que las acompañan y que proporcionan un terminus ante quem de 300 d.C. (infra).

\section{3. ¿Una tercera fase de producción en Rabatún?}

Un silo tardoantiguo excavado en la parte baja del yacimiento de Los Villares (U.E. 200), junto a las estructuras tardías de la parcela 4, contenía un conjunto de ánforas correspondientes en su mayor parte al tipo Beltrán IIB característico de la segunda fase de actividad del alfar de Rabatún. Sin embargo, entre ellas se documentan también fragmentos de ánforas Beltrán IIB evolucionadas (Fig 13: 1), cuyas características formales han permitido que sean diferenciadas bajo la denominación de Puerto Real 1 (García Vargas y Lavado Florido 1996). No se han recogido fallos de cocción del tipo, aunque las pastas cerámicas de las piezas son en todo idénticas a las del resto de las producciones del alfar, por lo que puede proponerse, como hipótesis a contrastar en las próximas campañas de excavación en la zona, que las Puerto Real 1 de Rabatún son de fabricación local, en cuyo caso, serían producciones correspondientes a una tercera fase del taller alfarero.

\section{LAS CERÁMICAS DEL ALFAR ROMANO DE RABATÚN}

\section{1. Ánforas}

Las ánforas de Rabatún ofrecen la oportunidad de retomar el estudio de la evolución formal de los contenedores gaditanos entre el siglo I a.C. y el II d.C., al menos en lo referido a algunas de las formas más características del elenco regional durante este período. Ello es así, porque, en general, se observa en el material anfórico del alfar, la presencia de individuos pertenecientes al menos a tres "generaciones" diferentes de las producciones anfóricas gaditanas. Las dos más recientes 
corresponden a los dos períodos cronológicos a los que pueden atribuirse las estructuras excavadas (supra); la más antigua está representada por materiales que comparecen con carácter aparentemente residual en las unidades de la primera fase de producción.

Las pastas cerámicas de todas las producciones que se citan como locales son muy homogéneas a lo largo de todo el período constatado de producción del alfar, tanto para las ánforas como para las cerámicas comunes. Se trata de pastas amarillas (L 91) a rosas (M 6970), duras, de matriz muy homogénea y granular, ligeramente arenosas, de fractura irregular, con gran cantidad de desgrasantes de cuarcita de pequeño tamaño $(1 \mathrm{~mm})$ transparentes y con colores variados, escasos hematites, fendas blancas escasas (feldespatos) y microfósiles muy dispersos.

\subsubsection{Primera "generación” de ánforas romanas de la bahía de Cádiz}

\section{Dressel 1}

Entre los materiales "residuales", documentados en su mayoría en la fosa-vertedero U.E. 640, contamos con fragmentos de borde y de cuerpos de ánforas del tipo Dressel 1 elaboradas con pastas de origen local o exógeno.

Las Dressel 1 locales corresponden a las variantes B y C, cuya manufactura en la bahía de Cádiz se documenta a lo largo del siglo I a.C. (Lagóstena Barrios 1996; García Vargas 1998, 2001). La morfología general de la mayor parte de los bordes del alfar de Rabatún se acerca a la de la variantes mayoritariamente producidas en la bahía gaditana, la Dressel 1C (Fig. 10: 1-2), aunque ciertas piezas (Fig.10: 7) podrían asimilarse a ánforas de la variante B de la Dressel 1 cuya producción en la Bahía no es desconocida (García Vargas 2001: 62). Las Dressel 1 C de los talleres cerámicos de la calle Javier de Burgos (García Vargas 1996, 1998; Lagóstena Barrios 1996; Lagóstena Barrios y Bernal Casasola 2004) del Jardín de Cano de El Puerto de Santa María (López Rosendo e.p.) son tal vez las mejor conocidas desde el punto de vista tipológico (para el resto cf. Lagóstena Barrios 1993-94, 1996) pero no debe olvidarse que en el Museo Arqueológico de Jerez (Fig. 10: 8) se conservan algunos ejemplares de Dressel $1 \mathrm{C}$ locales de procedencia desconocida cuya proximidad formal y macroscópica con las de Rabatún es notable (García Vargas 1998: fig. 73, 2; 2001: fig. 7, 5).

Las Dressel 1 de importación que, por las características de la pasta pueden considerarse de procedencia campana están representadas por bordes y hombros (Fig. 10: 3 y 6) con características morfológicas asimilables a las de las ánforas Dressel 1B.

\section{Ovoides gaditanas}

Definidas con carácter "provisional" hace más de una década (García Vargas 1996), las llamadas Ovoides gaditanas" se consideran el origen de las series salsarias béticas altoimperiales, especialmente de las del grupo 9-10 de Dressel. Su proximidad tipológica con las Haltern 70, las LC 69, las Ovoides del Guadalquivir (Almeida 2008) y de la futura Lusitania (Morais 2003) las sitúan con claridad dentro de este primer grupo de ánforas de tipología romana de la Ulterior con personalidad propia que hace su aparición en los primeros decenios del siglo I a. C.

Las Ovoides gaditanas se relacionan formalmente muy de cerca con las Ovoides del Guadalquivir, especialmente con las Ovoides 4 de Rui de Almeida (2008: 100-104), de las que se distinguen especialmente por la forma peculiar de las asas, de sección ovalada, con dorso recorrido por varias acanaladuras y de perfil marcadamente circular con ligero codo en la parte superior. Ello las distingue de las ánforas del tipo Ovoide 4 del Guadalquivir, con asas con profundo surco central y codo superior caído. También los bordes de las Ovoides gaditanas, a pesar de su enorme variabilidad, se distinguen de los de las Ovoides del Guadalquivir, siendo estos últimos similares a los de las Haltern 70 antiguas, mientras que las gaditanas parecen preludiar a los de las 7-11 iniciales, a veces con leves indicios de molduración en la pared exterior del borde. El pivote hueco no parece, sin embargo, exclusivo de las Ovoides gaditanas, pues aunque las Ovoides del Guadalquivir suelen llevarlo macizo, como las Haltern 70 , lo cierto es que en determinados talleres, como los alfares de Carmona, el pivote corto y hueco es mayoritario.

Dentro del grupo de las Dressel 7-11, la forma que presenta más afinidades con la Ovoide gaditana es la Dressel 10, hasta el punto de que en su mayor parte las Ovoides gaditanas pueden ser consideradas como Dressel 10 "arcaicas", aspecto éste que no deja de tener implicaciones para el alfar que estudiamos, como oportunamente se señalará más adelante.

Los bordes de Rabatún atribuibles al tipo Ovoide/ Dressel 10 antigua proceden de la canalización (Fig. 11: 5 y 17) y del vertedero tardío 700 (Fig. 11: 23). Son en todo similares a los recientemente publicados (Morais 2003: fig. 335 y 7) como procedentes de Castelo da Lousa, que se fecha hacia mediados del siglo I a.C., 
por lo que, como sucede con las Dressel 1 de los contextos que estudiamos, las consideramos residuales en los mismos

\section{Oberaden 83}

Precedentes de las ánforas olearias globulares del tipo Dressel 20, a través seguramente de un tipo intermedio denominado Haltern 71/Dressel 20, se las distingue por sus amplios cuerpos ovoides rematados en pivotes cónicos macizos. Cuando sólo se documentan ejemplares fragmentarios, estos se pueden distinguir por sus bordes redondeados al exterior y sus asas de perfil circular y sección ovoide con acanaladura dorsal, muy similares, por tanto, a las de las Ovoides 4 del Guadalquivir y a las de las Haltern 70 de la misma procedencia, aunque más cortas.

Las Oberaden 83, como precedente de las ánforas olearias béticas, fueron producidas fundamentalmente en el valle del Guadalquivir, donde están constatadas en alfares de Carmona (material inédito) y en depósitos tardorrepublicanos de Sevilla e Itálica (García Vargas e. p.). Algunos ejemplares del alfar de Jardín de Cano (Puerto de Santa María) deben considerarse de hecho como importaciones del valle del Guadalquivir por las características de sus pastas cerámicas (cf. López Rosendo e. p.).

A pesar de su carácter de contenedor más propio de los alfares del interior del valle bético, no faltan testimonios costeros, como en la bahía de Algeciras (El Rinconcillo: Fernández Cacho 1995: fig. 7, 12-1), donde no se especifica el aspecto de la pasta cerámica, por lo que su pertenencia a las producciones locales es hipotética, y en la bahía de Cádiz, donde, con pasta local, se documenta en la plaza de San Antonio de la ciudad de Cádiz, junto a Ovoides gaditanas (García Vargas 1998: fig. 67.1) y, como producción propias del alfar, en Rabatún en las fosas 650 (Fig. 10:10) y 640 (Fig. 10: 9 y 11).

Tanto en Carmona, como en Itálica o Jardín de Cano (Puerto de Santa María) las Oberaden 83 se hallan acompañadas por ejemplares del tipo LC 67 y tipos relacionados (Ovoide 5 del Guadalquivir) y por Dressel 1 terminales, tanto itálicas como locales, lo que indica que esta primera generación de ánforas de la UlteriorBética es la que verifica la transición desde las imitaciones tout court de contenedores itálicos a la creación de un repertorio propio que "cristalizará" ya en la segunda mitad del siglo I a. C. (García Vargas 2009) y se prolongará a lo largo del siglo siguiente hasta época flavia al menos.

\subsubsection{Segunda "generación” de ánforas romanas de la bahía de Cádiz}

Dressel 9/10

Como tal puede clasificarse un ejemplar casi íntegro (Fig. 11: 1), del vertedero 640 que presenta una enorme similitud con el resto de los ejemplares de Dressel 7-11 del alfar por su cuerpo ovoide y sus asas de perfil redondeado y ligero resalte en el codo. Sin embargo, otros parámetros, como la menor altura del cuello con relación a su anchura y los hombros de tendencia horizontal más marcada la aproximan a la morfología de las Dressel 9 contemporáneas. Una distinción similar entre Dressel 7-11 de cuello corto (Dressel 9/10) y de cuello alto (Dressel 10B) puede observarse entre los ejemplares augusteos del pecio Sud Perduto 2, particularidad que no ha dejado de señalarse por la editora del naufragio (cf. recientemente Bernard 2008) quien, no obstante, prefiere adscribir ambas variantes al tipo Dressel 9. Por nuestra parte, la similitud del perfil de las variantes de cuello alto de Rabatún con el diseño del tipo $\mathrm{n}^{\circ}$ 10 de la tabla de Dressel nos aconseja mantener dicha variante dentro de esta categoría, con la indicación de que corresponde al subtipo B de la clasificación de García Vargas (1998).

\section{Dressel 10}

Como se ha indicado, puede mantenerse con carácter general que las Dressel 10 prolongan a lo largo de época imperial temprana las características generales de las Ovoides gaditanas de época republicana (García Vargas 2006), de las que proceden, si no es que éstas son la variante "arcaica" de aquéllas, pues ambas se caracterizan por asas de perfil de tendencia circular con codo ligeramente levantado y un cuerpo ovoide más o menos voluminoso.

Sin embargo, mientras que un conjunto de ánforas de la forma 10 (subtipo C) mantuvo más o menos las características formales de las Ovoides gaditanas (cuello y asas cortas, pivote poco desarrollado), aumentando si acaso el diámetro máximo del cuerpo (García Vargas 1998: 90-91), hasta época tiberiana al menos, otro grupo (subtipo B) evolucionó a partir de esta tipología ovoide hacia las últimas décadas del siglo I a.C. y primeras de la centuria siguiente, evolución que se verificó en la acentuación de las molduras del borde, que ya no se presenta normalmente recto, sino exvasado. Se constata igualmente un crecimiento apreciable en altura del cuello, lo que trae como consecuencia el 


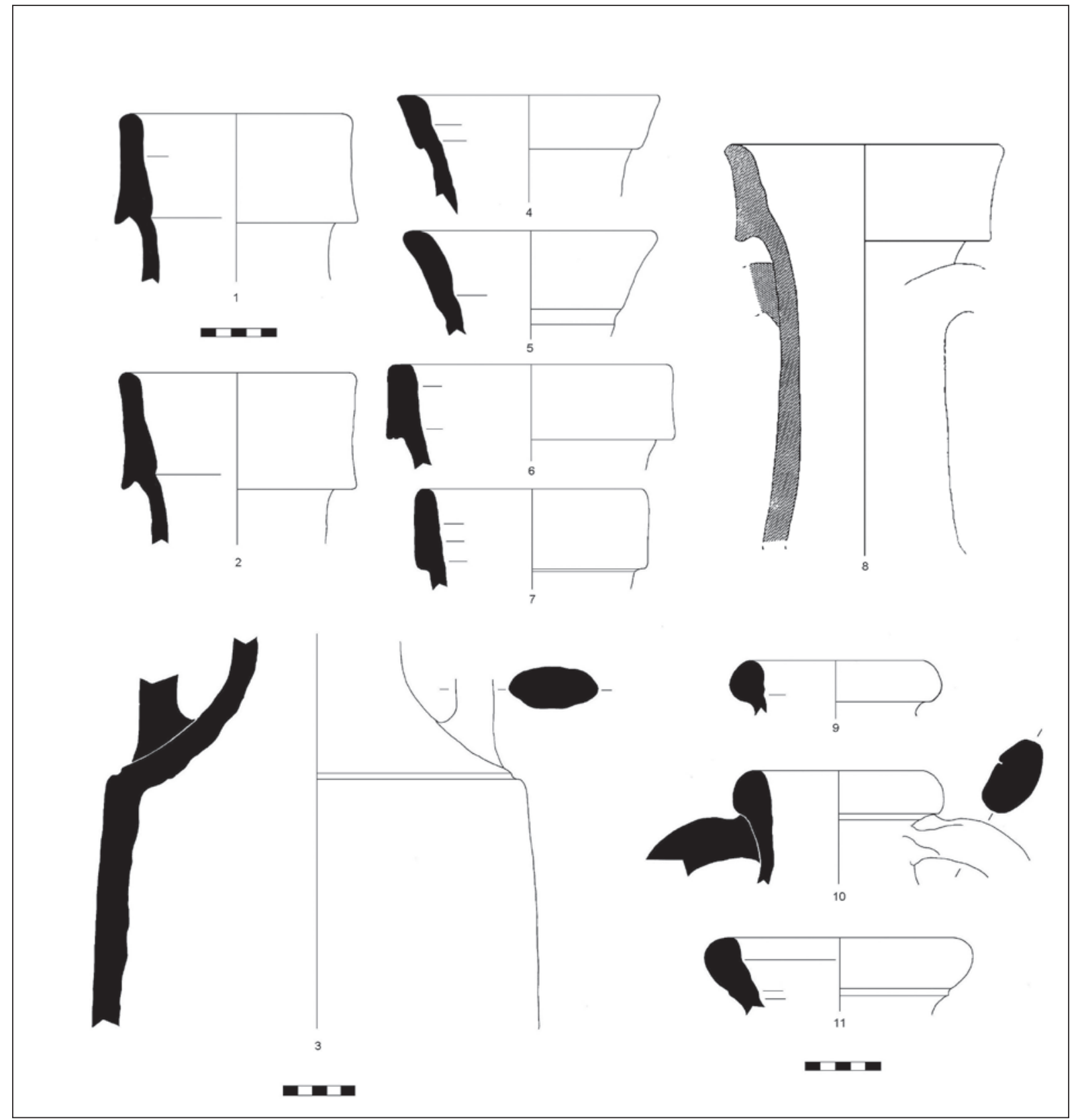

Figura 10. Rabatún.

1-2: Dressel 1B y C de producción local

3: Dressel 1 itálica

4-5: Haltern 70 con pastas del Guadalquivir

6: Dressel 1B de producción local

7: Dressel 1B itálica

8: Dressel 1c de producción local y procedencia desconocida depositada en el Museo Arqueológico Municipal de Jerez 9-11: Oberaden 83 de producción local. 
alargamiento de las asas (que pierden el perfil semicircular, pero mantienen el ligero resalte del codo), y del pivote (Fig. 11: 4) (García Vargas 1998: 87-88).

Los ejemplares de la fosa 640 de Rabatún corresponden a esta tipología de Dressel 10B (cf. fig. 11: 2 y 3), y demuestran que las Dressel 10 de cuello alto imperiales mantuvieron la tendencia ovoide del cuerpo propia de sus precedentes republicanos. Es probable que al lo largo de la época julio-claudia se produjera en esta variante un ensanchamiento progresivo de la parte inferior que daría lugar al surgimiento de la tipología más avanzada de las Beltrán IIB, en algún caso a través de un tipo intermedio denominado Dressel 11.

El tipo Dressel 10 parece mayoritario entre las producciones imperiales de Jerez de la Frontera y El Puerto de Santa María, donde suele comparecer acompañado de ánforas del tipo Dressel 9 o Dressel 9/10, muy similares en sus parámetros formales, aunque, como se ha visto con cuello y asas más cortos. En Rabatún es posible distinguir dos morfologías de borde que seguramente son indicativos de una cronología ligeramente diferente como se indicará al tratar de la datación de cada una de las estructuras del alfar y de sus materiales.

Los bordes de Dressel 10 (y eventualmente Dressel 9/10) de la zanja $\mathbf{6 5 0}$ presentan bordes casi rectos o ligeramente exvasados con desarrollo similar de las molduras superior e inferior y muy frecuentemente una pequeña moldura o listel en la base de esta segunda moldura (Fig. 11: 6, 7, 13-16). Puede decirse que están, morfológicamente, más cerca de las características de los bordes de Ovoide gaditana.

Los bordes de la cubeta 640 son, como en la Dressel 9/10 casi completa, más inclinados hacia el exterior, con una moldura superior más saliente y redondeada, y carentes, por lo general, de la fina moldura basal (Fig. 11: 1,18 y 24).

Creemos que esta dicotomía responde a un ligero desfase temporal, con prioridad cronológica de los bordes del primer grupo sobre los del segundo. Los ejemplares del primero serían, pues, residuales en la cubeta 640 (Fig. 11: 19), donde predominan los del grupo segundo, y ambos lo serían en el vertedero 700 (Fig. 11: 8-12 y 20-23).

\section{Epigrafía}

Por otra parte, los únicos elementos epigráficos constatados en el alfar comparecen sobre ánforas de la forma 10 (Fig. 11: 3 y 25) o sobre fragmentos atípicos que, dada su cronología, deben corresponder a estas producciones o a Dressel 9/10 (Fig. 15: 1-2). Se trata de grafitos ante cocturam, a veces muy incompletos, que, cuando pueden ser interpretados corresponden a numerales. Todos proceden, como se hay indicado, de las estructuras de la primera fase de producción: la cubeta 640 (Fig. 11: 3 y 25: numerales sobre el cuello de Dressel 10: XX y II respectivamente) y de la zanja 650 (Fig. 115: 1-2), muy fragmentados y de difícil interpretación, aunque tal vez sean también numerales.

\subsubsection{Tercera "generación” de ánforas romanas de la bahía de Cádiz}

\section{Beltrán IIA}

Un fragmento procedente de la UE 700 (Fig. 12: 12) puede ser asignado a la forma Beltrán II A, un contenedor salsario característico de la fase altoimperial avanzada que en la bahía de Cádiz no parece comenzar a fabricarse antes de época tiberiana y en cuyo estadio inicial de producción se caracteriza por cuerpos ovoides o piriformes, cuello y asas rectos y altos, borde triangular y ancha boca. Las Beltrán IIA, presentan, pues, características que permiten suponer un desarrollo formal a partir de las Dressel 7 locales (infra), con formas intermedias que se incluyen normalmente bajo la denominación Pompeya VII, pero que quizás sea mejor considerar como Dressel 7 terminales.

La Beltrán IIA de Rabatún se aparta de la morfología canónica del tipo en lo que respecta a la forma del borde, menos desarrollado y proyectado que los habituales del tipo, aunque mantiene la tendencia subtriangular. Bordes similares se conocen en otros contextos de producción de Jerez de la Frontera, como el alfar de El Torno-Cementerio de San Isidro (García Jiménez et alii 2004: fig. 4) y Puerto Real (Puente Melchor) a lo largo de los años finales del siglo I y la primera mitad del II d. C (subtipo D: García Vargas 1998: figs. 56: 1, 3 y 5), fechas que resultan consistentes con las que se pueden atribuir a la UE $\mathbf{7 0 0}$ de Rabatún a partir de la TSH del mismo contexto (infra).

\section{Beltrán II B}

Ánfora de amplia boca acampanada, con borde triangular caído y a menudo indiferenciado de un alto cuello que, sin solución de continuidad, da paso a un cuerpo piriforme rematado en alto pivote hueco. Las asas, muy altas, subrayan la longitud del cuello y descansan en unos hombros escasamente marcados. 


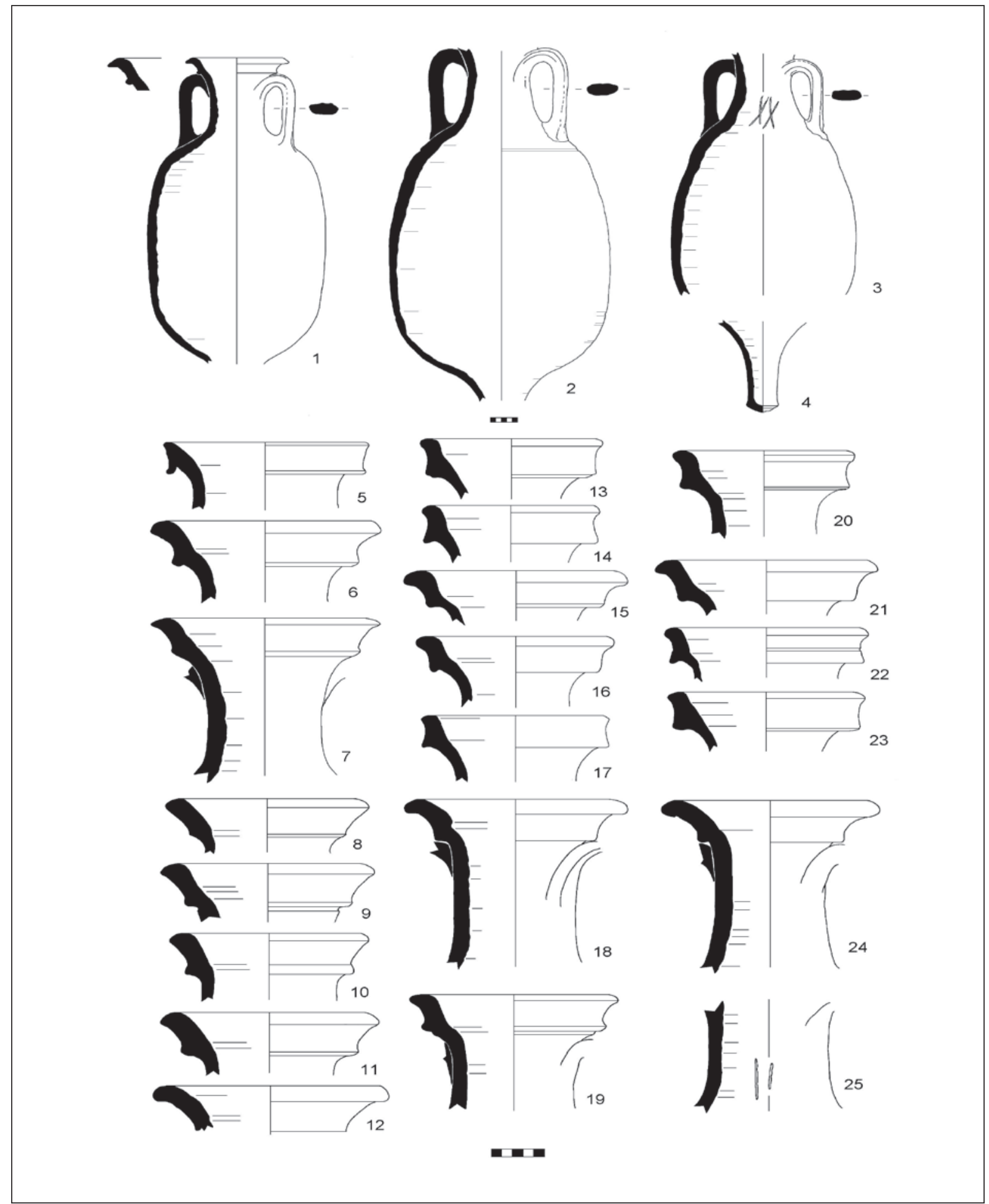

Figura 11. Rabatún. Primera fase de producción: 1: Dressel 9/10

2-4, 6-16, 18-25: Dressel 10B

5, 17: Ovoide gaditana. 
En los ejemplares de la variante más antigua del tipo (II Ba), se observan el característico borde triangular aún destacado de la pared del cuello mediante una moldura y los hombros ligeramente diferenciados del resto del cuerpo. A partir de los decenios finales del siglo I se constata una segunda variante, Beltrán II Bb (García Vargas 1998: 108-109), que se producirá a lo largo de todo el II d. C. Este subtipo se caracteriza por la sinuosidad de sus líneas y por la esbeltez general.

Las Beltrán II B son muy mayoritarias en los vertidos de la U.E. 670 (Fig. 12: 1, 3-7, 8 y 10), donde comparecen junto a IIA y bordes residuales de Dressel 10 (Fig. 11: 8-12 y 20-23) y el "muro" de ánforas U.E. 700 (Fig. 12: 9), de donde probablemente procedan los ejemplares completos del Museo de Jerez de la Frontera.

Por lo demás, tal vez merezca la pena considerar que el amplio borde triangular de arranque indiferenciado del cuello no es tal vez sino el final del proceso de desarrollo y estilización de los bordes de Dressel 10 de la fase anterior, en el sentido de una mayor esbeltez y desarrollo de la parte superior del borde, con pérdida final de la moldura inferior que se había ido simplificando ya en las Dressel 10 del segundo grupo. Ello refuerza, a nuestro juicio, la idea de cierta una continuidad morfológica entre las Dressel 10 y las Beltrán II B de Rabatún (infra).

\subsubsection{Cuarta "generación" de ánforas romanas de la bahía de Cádiz}

\section{Puerto Real 1}

Un conjunto exiguo de materiales anfóricos (Fig. 13) procedentes del relleno del silo 200 en el sector 4 de la excavación presenta entre sus componentes algunos ejemplares de ánforas Puerto Real 1 (Fig. 13: 1). Se trata de ánforas derivadas de las Beltrán II tardías que se diferencian de éstas por un borde triangular más masivo que el de sus predecesoras, un cuello más corto y ancho, unas asas robustas y cortas, un cuerpo piriforme de grandes dimensiones y un pivote rodeado en su parte terminal, como las Keay XVI que de ellas proceden, por una moldura o anillo (cf. García Vargas 1998, 2001; García Vargas y Lavado Florido 1995, 1996). La cronología de estas producciones, mayoritariamente fabricadas en el alfar de Puente Melchor (García Vargas y Lavado Florido 1995), aunque se conocen otras alfares productores, como el de Albardonero, en San Fernando (Sáez y Sáez 2004) se centra en época severiana, aunque es posible que su fabricación arranque en época tardoantonina, en torno a los años setenta u ochenta del siglo II d. C. El resto de los fragmentos del mismo contexto corresponde a Beltrán IIB avanzadas (Fig. 13: 2-8).

\subsection{Cerámica común}

En muchos alfares de ánforas de la bahía de Cádiz, tanto al norte como al sur del Guadalete, se documenta también la manufacturan de cerámica común y elementos constructivos. Lo habitual es, sin embargo, es que estas producciones hayan recibido menor atención que las ánforas por parte de los investigadores, con lo que el repertorio básico de las formas de cerámica común manufacturada en la bahía de Cádiz en época romana permanece sin realizar [pero vide Sáez Romero (2005) para los repertorios púnicos, cuya tipología aparece siempre precedida por las siglas GDR].

La mayoría de las comunes de Rabatún proceden de los vertidos de la fosa $\mathbf{6 5 0}$, correspondiente a la primera fase conocida de producción. Se trata de un repertorio bastante coherente con unas fechas augusteas, que son las propuestas para estas unidades, si bien no resulta evidente que todas ellas hayan sido fabricadas en el alfar. Por lo que hace a la morfología general, cabe distinguir entre formas abiertas y cerradas.

\subsubsection{Comunes de la primera fase detectada de producción}

Formas abiertas

Cuencos. De larga tradición en el elenco púnico y turdetano del SO. En la fosa 640 se documentan ejemplares con forma hemiesférica próximos al tipo GDR 1.3.1. (Fig. 17: 2), así como otros de perfil más bajo, derivados de los GDR 1.2.1 (Fig. 17: 3) y con labio igualmente romo. En la fosa $\mathbf{6 5 0}$ se documentan los de borde apuntado (Fig. 17: 1) similares al tipo púnico-gadirita GDR 1.2.2.

Cazuelas de borde bífido (Fig. 17: 5-6), más cercanas por su morfología a los prototipos itálicos Vegas 14 que a los púnicos tardíos (GDR 11.1.1). Proceden del relleno de la UE 650. Al menos un ejemplar es una Vegas 14 itálica (Fig. 17: 6).

Tapaderas. Cercanas en su morfología a los prototipos itálicos (650) de la forma IT 7F y G (Fig. 17: 7-8).

Opérculos o tapaderas de ánfora de botón macizo y ala recta (Fig. 15: 5) y de botón perforado y ala vuelta (Fig. 15: 6). Proceden de los rellenos de la fosa 640. 


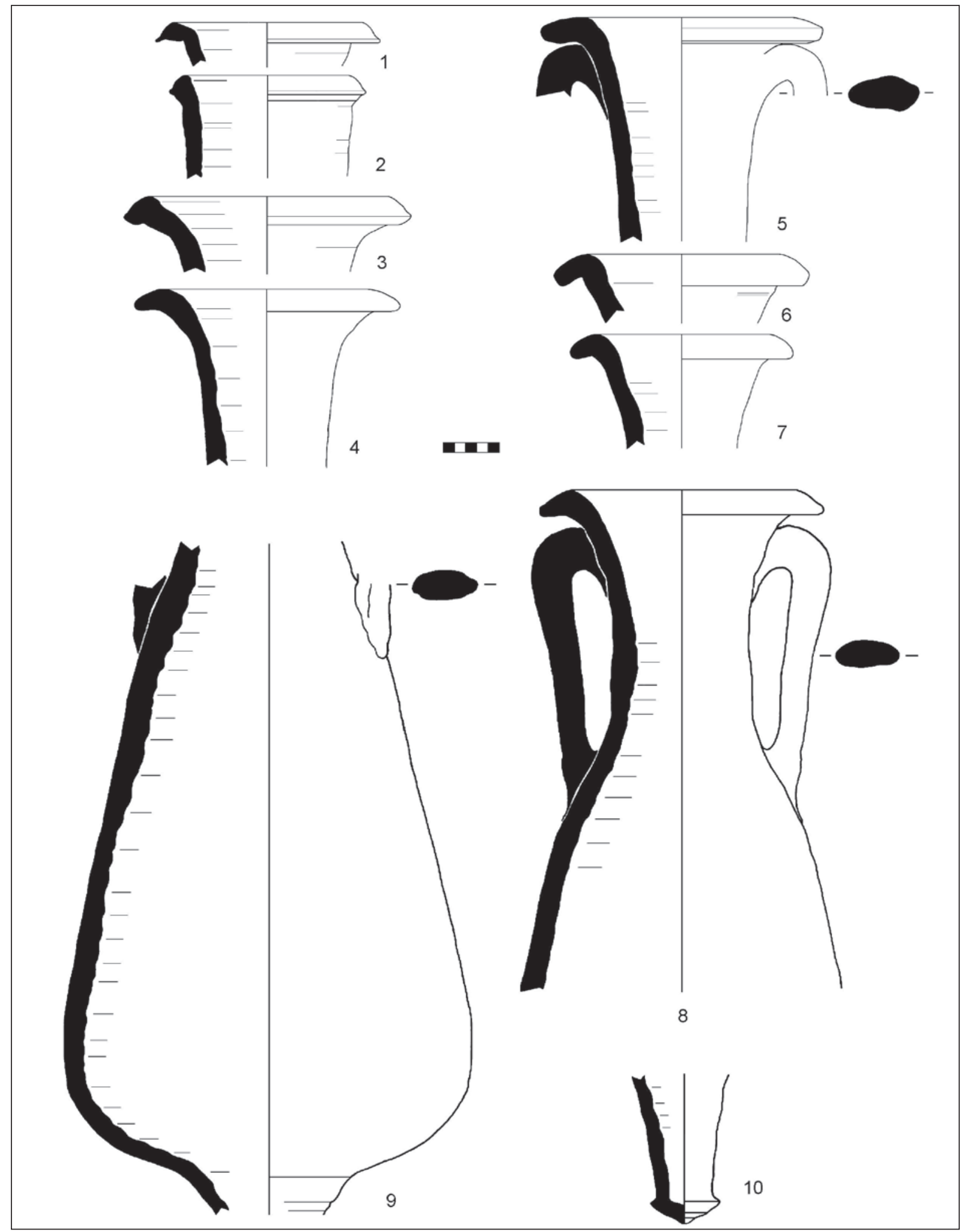

Figura 12. Rabatún. Segunda fase de producción: 1, 3-10: Beltrán IIB 2: Beltrán IIA. 


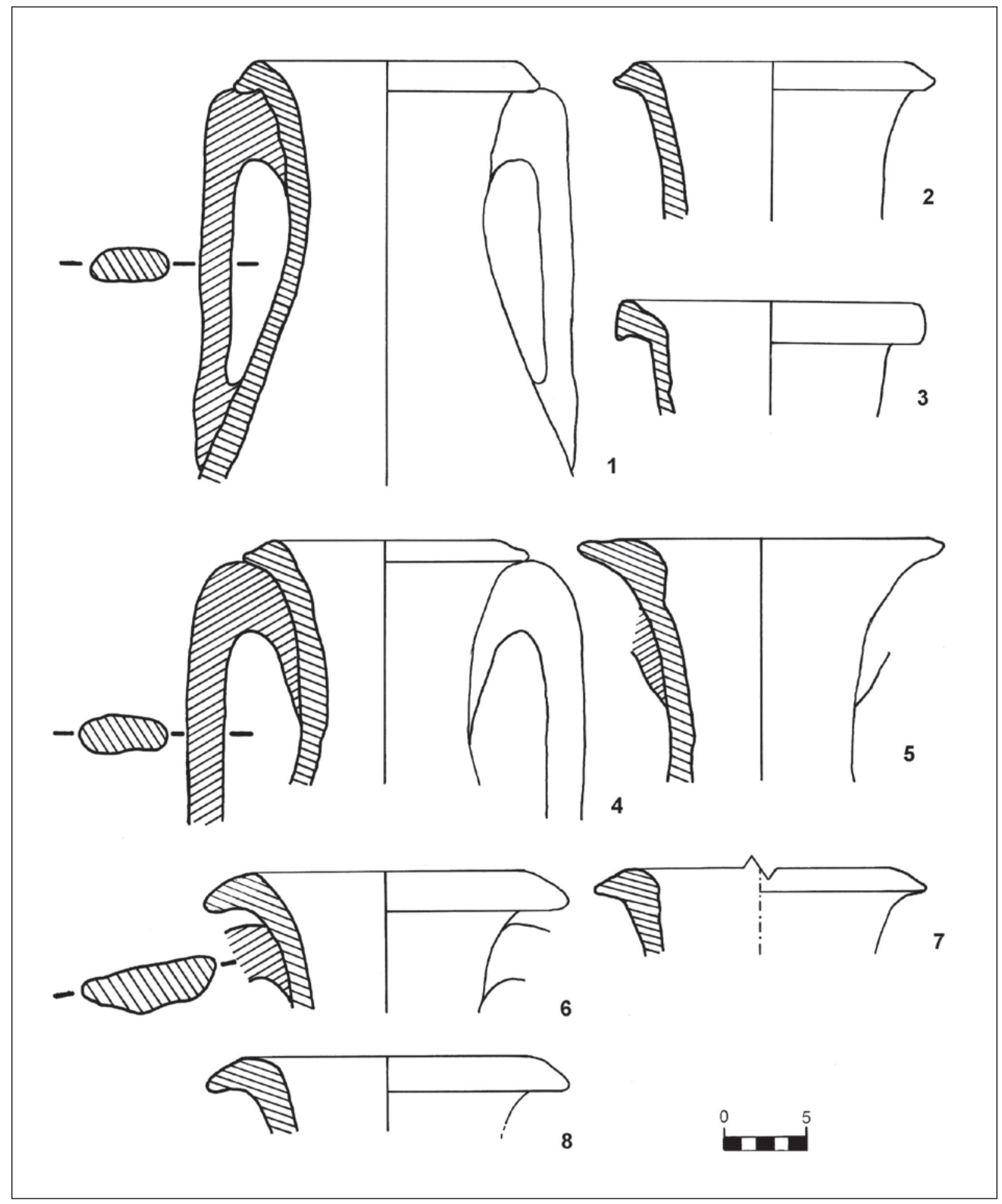

Figura 13. Rabatún. ¿Tercera fase de producción?:

1. Puerto Real 1

2-8, Beltrán IIB. 


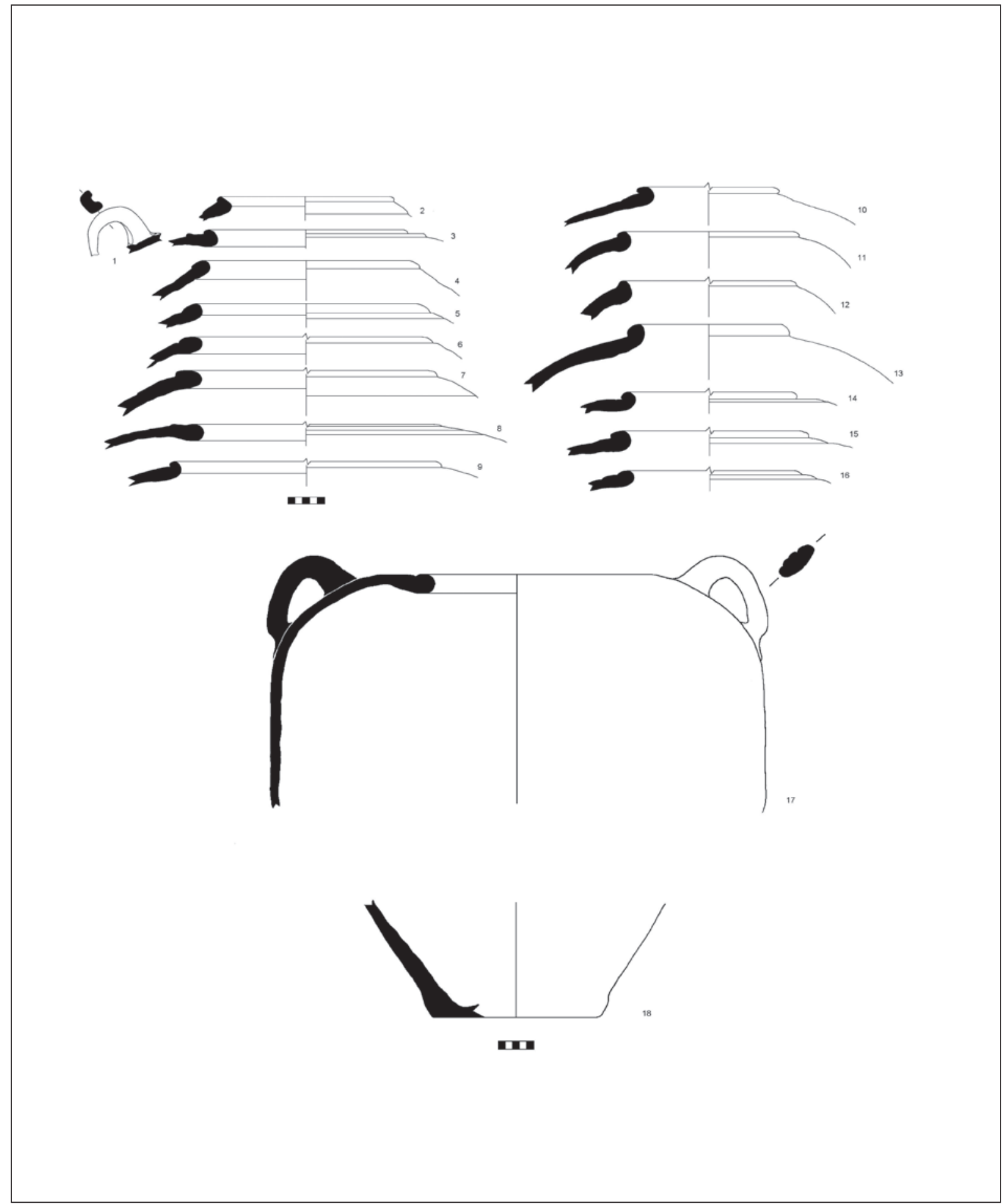

Figura 14. Rabatún. Dolia.

1-9: superficie: pastas locales

10-16: primera fase de producción: pastas del valle del Guadalquivir 17-18: primera fase de producción: pastas locales. 


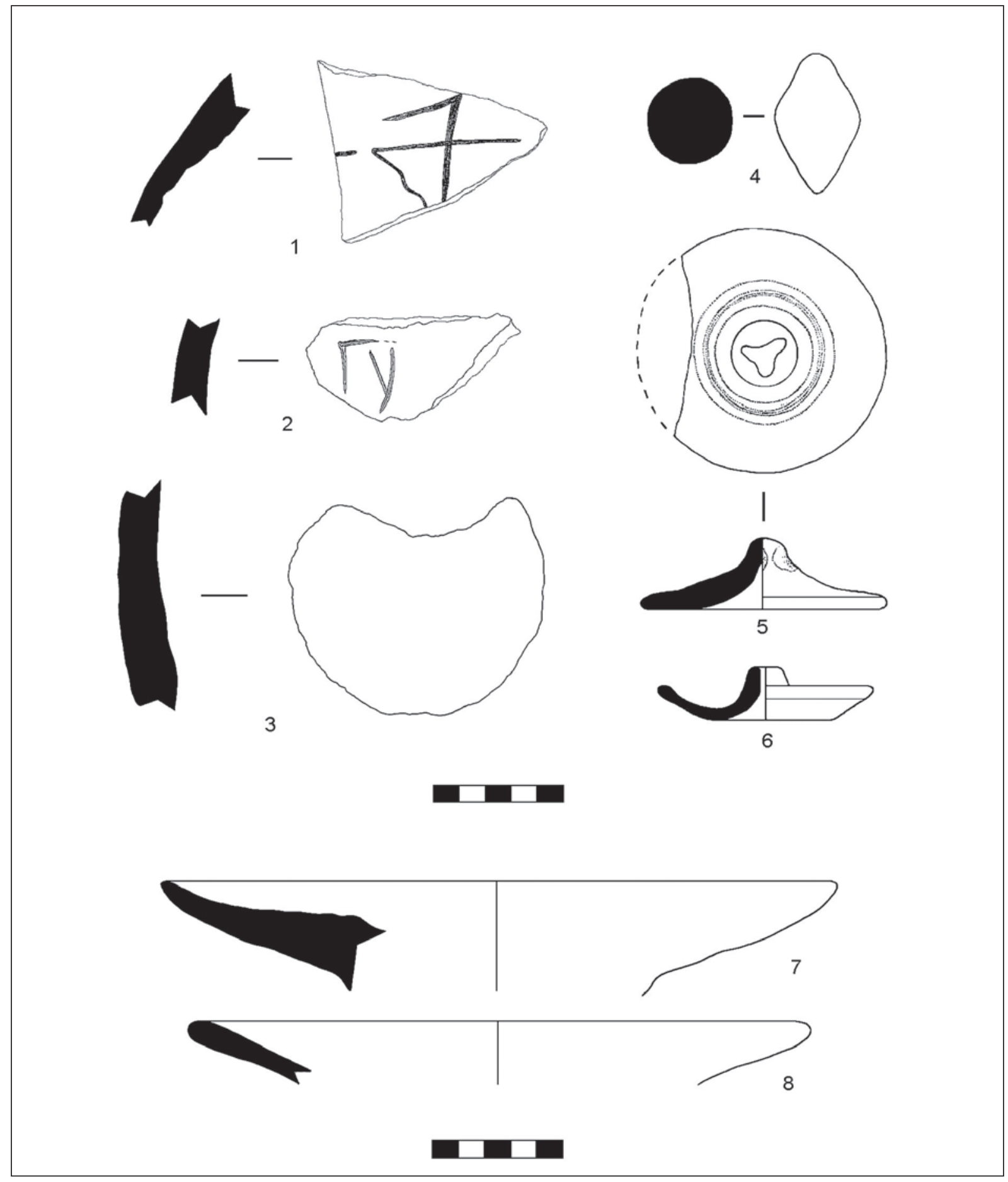

Figura 15. Rabatún. Primera fase de producción:

1-2. Atípicos con grafitos ante cocturam
3. Ficha recortada
4. "glande" cerámico
5-6: opercula

7-8: cuencos-tapadera. 


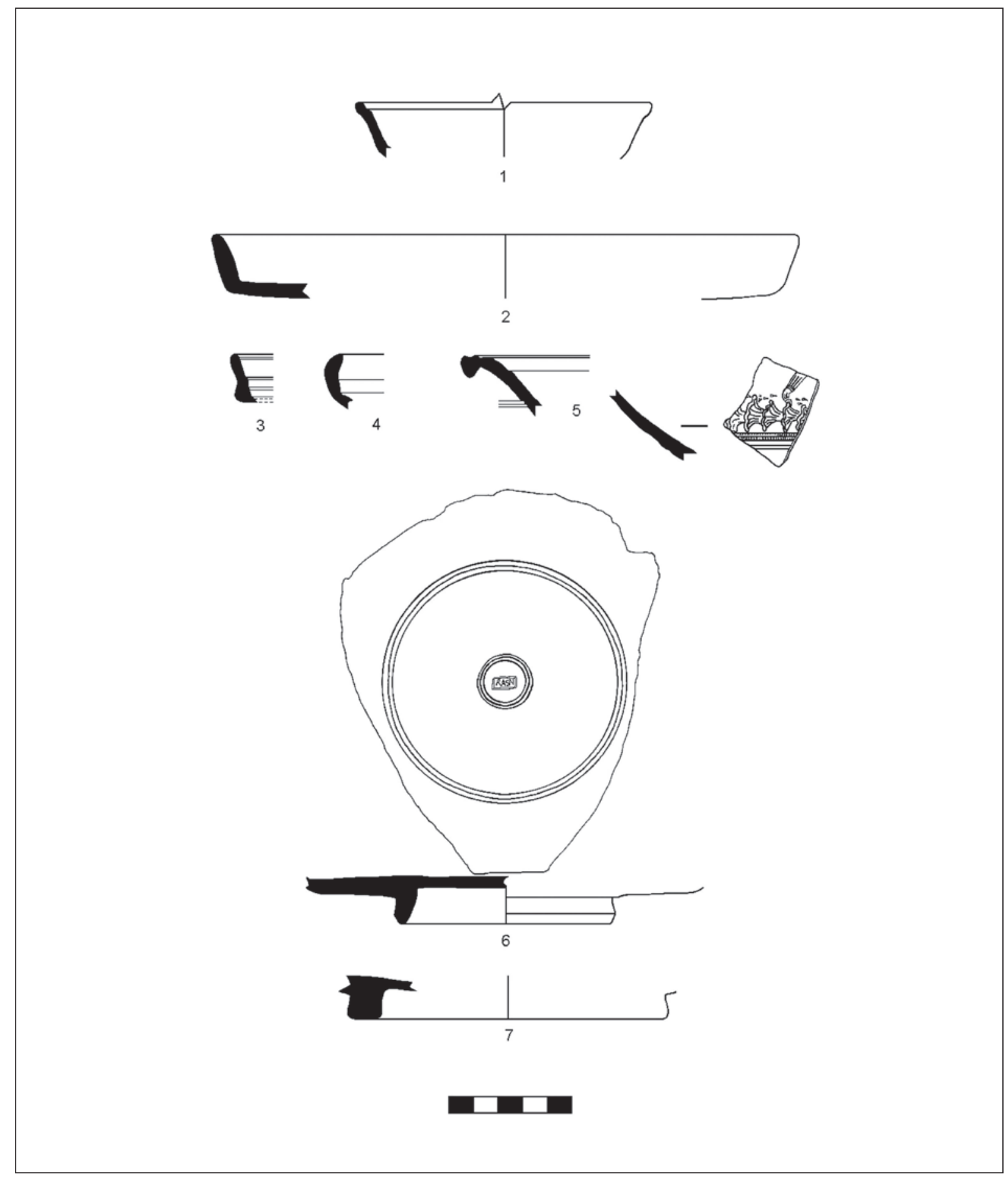

Figura 16. Rabatún. Cerámica de mesa datante de la primera fase de producción (relleno de fosa 650): 1. Cerámica tipo Peñaflor

$$
\text { 2-7. TSI }
$$


Formas cerradas

Jarritas de cuello corto y borde moldurado (Fig. 18: 1) procedentes de la fosa $\mathbf{6 5 0}$ y frecuentes en contextos romanos regionales del cambio de Era y época julio-claudia

Jarras: de cuello alto y cilíndrico (Fig. 18: 2.) de la fosa 650, que parecen próximas por la forma de éste a los tipos tardogadiritas (GDR 10.0.0), aunque el abombamiento central del cuerpo es propio de las producciones romanas de época augustea y julio-claudia.

Ollas de borde horizontal (Fig. 18.4-5). De tradición itálica, se encuentran igualmente bien representadas en contextos augusteos y julio-claudios tempranos del Estrecho, costa mediterránea y valle del Guadalquivir. Conviven en los vertidos ejemplares de procedencia itálica y con pastas locales.

Urnas. Se trata de una forma de tradición local-regional, con gran tradición en el ámbito cultural púnicoturdetano y en el círculo del Estrecho. Comparecen en la fosa 640 con formas de borde similares a los de las urnas tardogadiritas (GDR 9.9.1) que coinciden con los de las urnas turdetanas de republicana final y augusteas (Fig. 18: 6); en el depósito 650 (Fig. 18: 7), con raíces en las formas gadiritas tardías (GDR 12.2.1), y de nuevo en los rellenos de $\mathbf{6 4 0}$ (Fig. 18: 8) con formas de borde y fondos similares a los de las urnas itálicas IT 1A, frecuentes en el siglo I a.C. y I d.C. Tanto en $\mathbf{6 4 0}$ (Fig. 18: 11 y 13) como en los rellenos de 650 (Fig. 18: 12) presentan bordes muy moldurados. Los fondos rehundidos de la fosa 640 son propios de los prototipos de Gadir y el valle del Guadalquivir (Fig. 18: 9).

Tinajas de 650, derivadas de la forma púnica 8.1.2., aunque con labios más moldurados al exterior que los de sus prototipos púnicos. El único ejemplar documentado (Fig. 18:10), corresponde a una producción exógena (Guadalquivir).

Tazas (Fig. 18: 3) de la fosa $\mathbf{6 4 0}$ derivadas de la forma 10C en Paredes Finas, con borde alto cóncavo y dos asas; aunque a diferencia de los ejemplares itálicos e ibicencos que parecen servir de modelo, presenta la parte baja del borde y el cuerpo profusamente decorados. A excepción de este detalle decorativo, la morfología, establecida seguramente ya en época augustea como parece sugerir el contexto 646 (interior de fosa 640) en que se documenta, parece haber encontrado un cierto éxito, convenientemente evolucionada, entre las producciones béticas de épocas julio-claudia y flavia.

Dolia (Fig. 14: 13-18) de la fosa 640 con borde entrante almendrado ligeramente marcado al exterior y también a veces ligeramente moldurado, asas de cinta acanaladas y fondo estrecho y plano. La mayor parte de ellos, sin embargo, presenta pastas propias del valle del
Guadalquivir, por lo que no deben adscribirse a las producciones del alfar.

\subsubsection{Comunes de la segunda fase detectada de producción}

\section{Formas abiertas}

Morteros de borde rectangular y acanaladura interna (Fig. 17: 7) procedentes del vertedero $\mathbf{7 0 0 .}$

Lebrillos o cuencos de borde exvasado (Fig. 17: 8) del mismo contexto.

\section{Formas cerradas}

Dolia (Fig. 14: 1-9) de la UE 700 de borde almendrado u ovoide con resalte exterior menos marcado, trayectoria recta del borde con respecto a las paredes del recipiente y a veces moldura o listón marcado en la transición entre el cuerpo y el borde (Fig. 14: 3 y 8).

\subsubsection{Comunes de superficie}

Lebrillos de cuello estrangulado y borde vuelto (Fig. 17: 9-10) similares a producciones gadiritas del tipo GDR 4.1.1., pero sobre todo a las formas tardoturdetanas de épocas republicana y augustea. Deben corresponder a la fase primera.

\subsection{Otras producciones}

\subsubsection{Materiales de construcción.}

Entre los materiales arqueológicos de los rellenos de la zanja 650 se documentaron algunos descartes de horno y fragmentos de tégulas e ímbrices. Las piezas sin fallos aparentes de cocción muestran pastas en todo similares al del resto de las producciones del alfar. Su escaso número y su carácter incompleto hacen imposible de momento un estudio en profundidad acerca de sus características morfométricas.

\subsubsection{Terracotas}

Lázaro Lagóstena, a quien agradecemos la información, y José M. ${ }^{a}$ Gutiérrez recogieron hace unos años tres o cuatro terracotas del alfar de Rabatún en un reconocimiento superficial del yacimiento anterior a la 

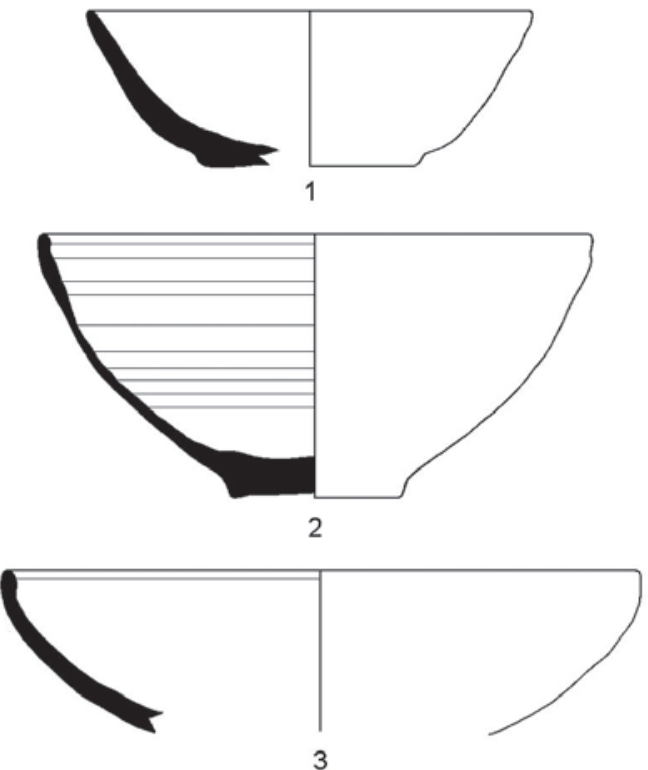
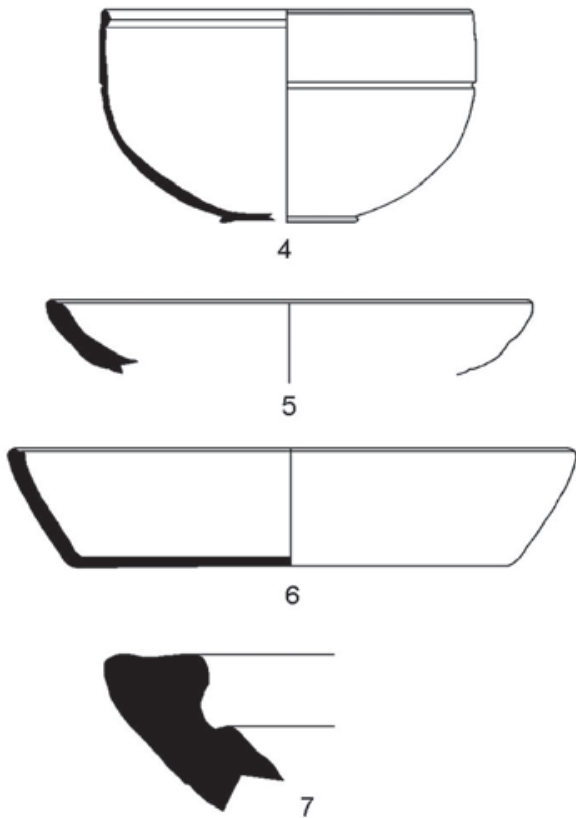
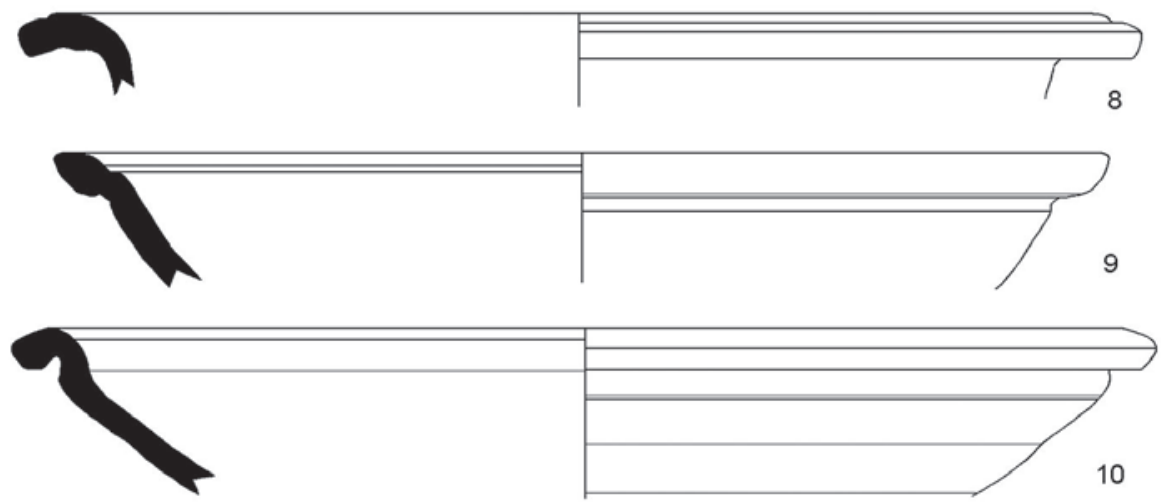

10

Figura 17. Rabatún. Primera fase de producción (relleno de fosa 650):

1-3 cerámica común local

4: bol de paredes finas itálico de la forma Mayet XXXIII

5: cazuela de borde bífido local

6: cazuela de borde bífido itálica Vegas 14

Segunda fase reproducción: 7: mortero local

$$
\text { 8-10: librillos locales. }
$$




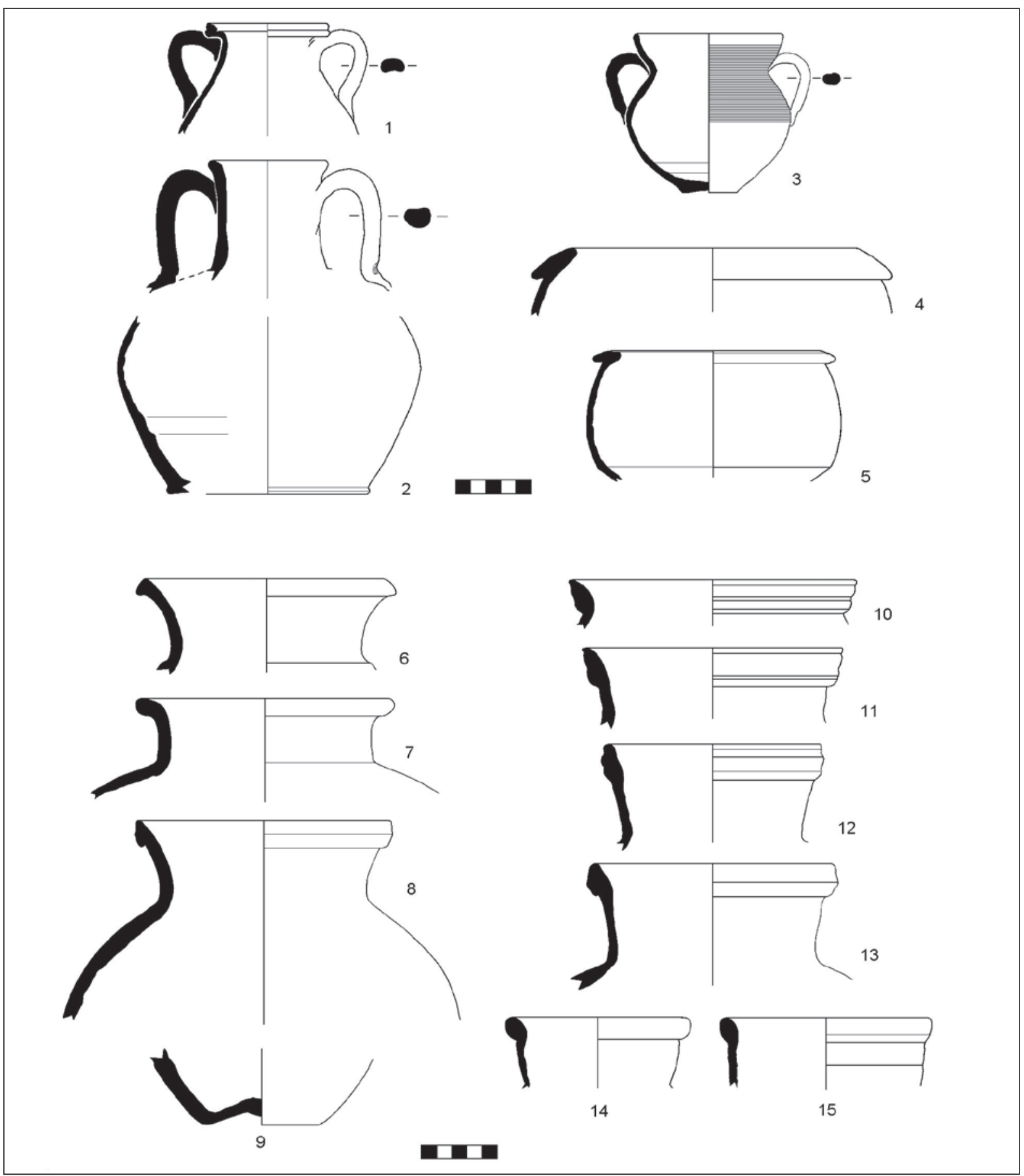

Figura 18. Rabatún. Cerámica común local de la primera fase de producción: 1-2: jarras

3: taza con asas

4-5: ollas con borde horizontal

6-9: urnas

10: tinaja

11-15: jarras

Todas de producción local, excepto 4 (itálica) y 10 (valle del Guadalquivir). 


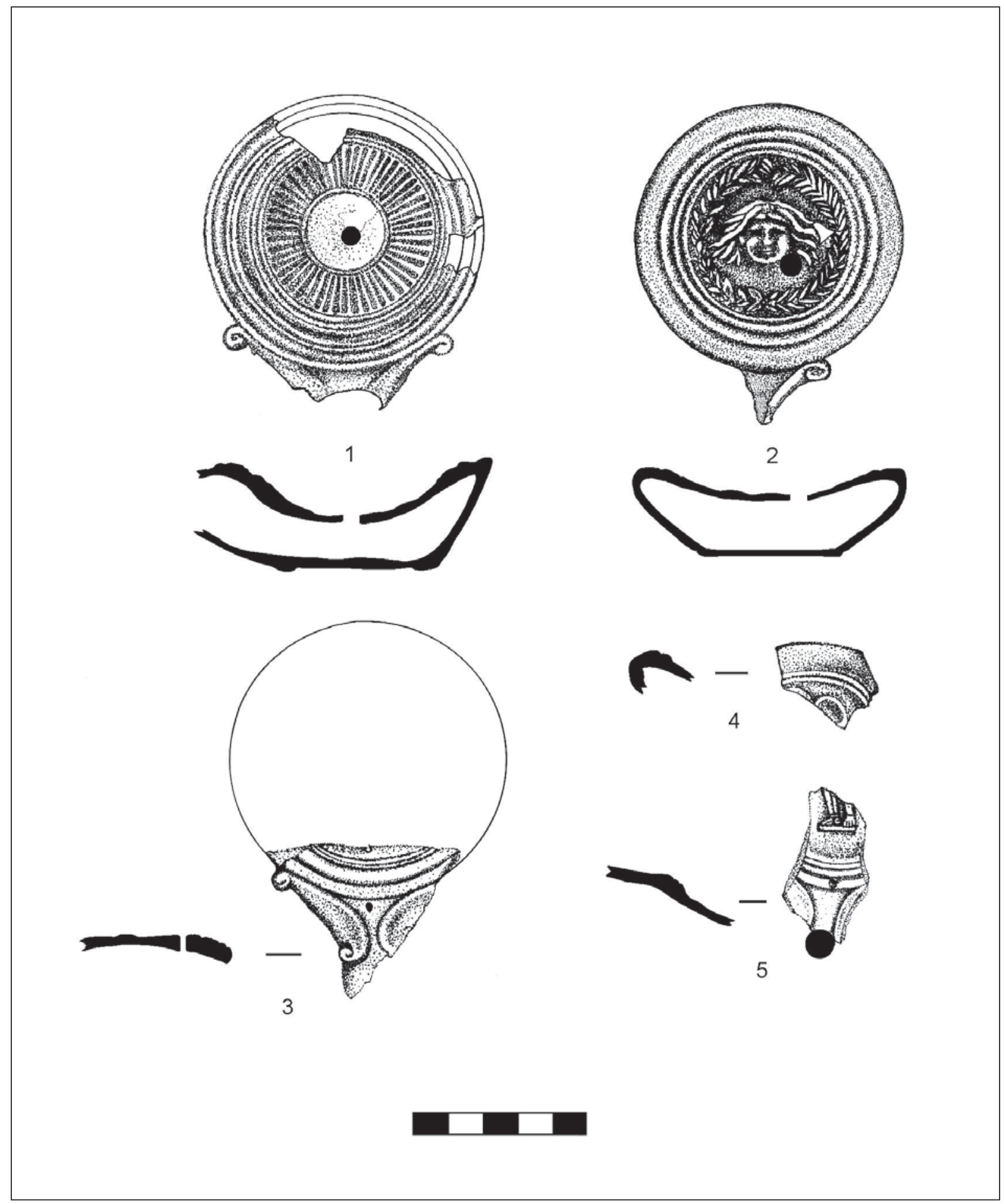

Figura 19. Lucernas itálicas procedentes de rellenos de la primera fase de producción:

1, 3-5 : Dressel 11/Leibundgut XII (rellenos de UE 650)

2. Dressel 11/Leibundgut XII: rellenos de UE 340. 
intervención arqueológicas. La que se muestra en la Fig. 20: 1 parece representar un tema religioso habitual en estas pequeñas piezas antropomorfas, cuya producción en el alfar es hipotética. Estas terracotas solían cumplir una función a menudo relacionada con el mundo religioso o funerario (Vaquerizo Gil 2004: 42 ss.) y se fabricaban por regla general en pequeños alfares urbanos o rurales dedicados a la cocción de las piezas más corrientes del menaje de cerámica común, de lucernas y de c Paredes Finas (Ramos 2008: 780). No faltan, sin embargo ejemplos en la Bética de producciones asociadas a talleres de ánforas y elementos de construcción (Bernal Casasola 1993).

\subsection{El material cerámico datante y \\ la cronología del alfar.}

La mayor parte de los fragmentos de cerámicas que pueden ofrecer dataciones más ajustadas que las de las propias ánforas se documentan en los rellenos de la zanja 650. Se trata de sigillatas itálicas, de cerámicas de Paredes Finas y de lucernas. De los rellenos de la fosa 640 procede un fragmento de lucerna y otro de Paredes Finas de producción bética, finalmente, del vertedero $\mathbf{7 0 0}$ dos fragmentos de TSH. La adscripción tipológica y la cronología absoluta de estos materiales dotantes es la que se recoge en el cuadro de la página siguiente.

Las fechas aportadas por la cerámica de paredes finas, la TSI y las imitaciones de Peñaflor sugieren que la unidad 650 debió colmatarse en torno a los primeros años del S. I d. C., pues los materiales citados coinciden en un tramo temporal datable grosso modo entre 20 a.C. y 20 d.C. Una cronología tardoaugustea o ya tiberiana para la formación de la unidad parece factible y no es incompatible con la de las lucernas Dressel 11 de volutas y pico redondeado correspondientes a la variante Leibundgut XII/Loeschcke V. La misma fecha puede atribuirse a un fragmento de borde de Haltern 70 de fabricación exógena al alfar (Fig. 10: 4), pues presenta pastas claramente atribuibles al Guadalquivir. Sin embargo, un segundo borde de Haltern 70 del Guadalquivir, más alto y exvasado, obliga a retrasar un poco la datación de la unidad. Aunque bordes altos se documentan ya en los años iniciales del s. I d.C. (Puig 2004), éstos presentan aún una clara separación con el cuello, mientras que el segundo de los ejemplares de la UE $\mathbf{6 5 0}$ tiene esta línea inferior muy atenuada (Fig. 11: 5), característica de las ánforas del tipo durante el segundo cuarto del siglo I d.C., que tal vez sea la datación correcta para la unidad.

Los elementos tipológicos para la datación de los rellenos de la fosa $\mathbf{6 4 0}$ son menores. Las lucernas Dressel
11 o de volutas y pico apuntado, presentan una articulación entre las volutas y el rostrum que, como en el caso de las de la fosa 650, es (Leibundgut 1977) la propia de época augustea o tiberiana. La presencia de un fragmento de pared de taza de Paredes Finas de la forma Mayet XLII, con superficie anaranjada, típica de la Bética, y decoración de hojas de piña (segunda mitad del siglo I d.C.: López Mullor 2008: 369), obliga a retrasar en el tiempo la formación de los vertidos que colmatan esta unidad, que creemos deben fecharse como muy pronto a mediados del siglo I d. C. y como muy tarde en época tardojulio-claudia o tempranoflavia, por la total ausencia de ánforas de las forma Beltrán II A y B.

La TSH del vertedero 700 y los escasos fragmento de la forma 9B de Hayes en TSC A lo fechan entre época flavia y los años centrales del siglo II d. C. Las ánforas, por su parte, responden a una morfología relativamente avanzada de los tipos IIA y IIB de Beltrán, encuadrable entre fines del s. I d.C. y la primera mitad del II d.C., faltando totalmente en estos vertido las tipologías "terminales" de ambas formas que las aproximan ya a los tipos tardoantoninos y severianos Augst 30-Puerto Real 1 y 2. (García Vargas y Lavado Florido 2005). Esta debe ser la fecha también del "muro" de ánforas UE 670.

Las ánforas Puerto Real 1 aparecen en la UE 200, lo que le daría una fecha de fines del II o comienzos del III d. C., pero resta aún por comprobar si se trata de producciones locales o no.

En conclusión, unas primeras estructuras de extracción de arcilla y de posible canalización amortizadas con vertidos cerámicos que delatan una actividad continuada entre épocas tardotiberiana (650) y tardojulioclaudia o tempranoflavia (640), y unos vertederos cerámicos de segunda fase $(\mathbf{6 7 0}, \mathbf{7 0 0})$, en uso desde por lo menos fines del s. I d. C. hasta quizás la mitad del siglo II d. C., con una hipotética fase final (200) ya en torno a época tardoantonina o severiana.

\section{CONTEXTUALIZACIÓN DE LAS CERÁMICAS DE RABATÚN EN PERSPECTIVA REGIONAL}

La publicación en los últimos años de tres importantes alfares romanos de la margen septentrional del Guadalete, ubicados en los términos municipales actuales de El Puerto de Santa María y Jerez de la Frontera, nos pone ante el proceso de desarrollo de las morfologías cerámicas regionales entre épocas tardorrepublicana y antonina.

Estos alfares son: Buenavista (Lagóstena Barrios 1996: 59; Mata Almonte y Lagóstena Barrios 1997; 


\begin{tabular}{|c|c|c|c|c|c|}
\hline UE & Clase & Tipo & Cronología & Otros & Fig. \\
\hline 640 & Lucerna & Dressel 11B/Leibundgut XII & Augustea-tiberiana & & 19.2 \\
\hline 640 & Paredes Finas & Mayet XLII & Claudio-Flavios & & - \\
\hline 650 & TS tipo Peñaflor & Martínez 1/Celti 14 & Augusteo-tiberiana & & 16.1 \\
\hline 650 & TSI lisa & Consp. 1.1 & $40-15$ a. C. & & 16.2 \\
\hline 650 & TSI lisa & Consp. 18 & 10 a. C.- 20 d. C. & & 16.3 \\
\hline 650 & TSI lisa & Consp. 4.5 & 10a. C. -10 d. C. & & 16.4 \\
\hline 650 & TSI decorada & Consp. R1 & 10 a. C - cambio de Era. & & 16.5 \\
\hline 650 & TSI lisa & Pie Consp. B.1.6 & Augusteo-tiberiana & & 16.7 \\
\hline 650 & TSI lisa & $\begin{array}{l}\text { Pie Consp. } \\
\text { b.2.3. }\end{array}$ & Augusteo & $\begin{array}{c}\text { Sello } R A S I N[I] \\
\text { en cartela rectangular. }\end{array}$ & 16.6 \\
\hline 650 & Lucerna & Dressel 11B/Leibundgut XII & S. I d. c. & & 19.1 \\
\hline 650 & Lucerna & Dressel 11B/Leibundgut XII & Augusteo-tiberiana. & & 19.3 \\
\hline 650 & Lucerna & Dressel 11B/Leibundgut XII & Augusteo-tiberiana. & & 19.4 \\
\hline 650 & Paredes Finas & Mayet XXXIIIb & 25 a. C. -20 d. C. & & 17.4 \\
\hline 700 & TSG & Forma $35 / 36$ & $60-160$ d. C. & & 20.2 \\
\hline 700 & TSH lisa & Forma $24 / 25$ & $40-150$ d. C. & & - \\
\hline 700 & TSH decorada & Forma $37 \mathrm{~b}$ & $70-100$ d. C. & & 20.3 \\
\hline 700 & TSC A & Hayes 9b & $80-160$ & & - \\
\hline
\end{tabular}

Lagóstena Barrios y Bernal Casasola 2004: 62, $\mathrm{n}^{\mathrm{O}}$ 42), Jardín de Cano (López Rosendo 2008) y Rabatún (García Vargas 1998; Lagóstena Barrios y Bernal casasola 2004: 60, n 35; López Rosendo 2008). Los tres coinciden en funcionamiento en época augusteo-tiberiana, siendo por ahora evidente una fase preimperial sólo en Jardín de Cano y una julio-claudia y flavio-antonina sólo en Rabatún.

En los tres lugares, sin embargo, y gracias a la presencia de material, aparentemente residual tanto en Buenavista como en Rabatún, puede seguirse el desarrollo de las tipologías anfóricas gaditanas entre mediados del siglo I a. C. y el primer cuarto del I d. C.

En una primera fase preaugustea, mal representada en Rabatún y Buenavista por materiales residuales, convivirían los últimos contenedores tardopúnicos del tipo 7.4.3.3 (Jardín de Cano, Buenavista) con imitaciones locales de Dressel 1C y ánforas Ovoides gaditanas (Jardín de Cano, Buenavista, Rabatún). Éstas últimas representan el primer horizonte formal de las Dressel 7-11, con morfologías muy próximas a las de las Dressel 10C, de las que se conocen dos ejemplares sin boca en El Almendral (García Vargas 1998: fig. 77, 1-2), alfar situado a escasamente un km. de Rabatún en el actual casco urbano de Jerez de la Frontera (García Vargas 1998: 189; Lagóstena Barrios y Bernal Casasola 2004: 58, n² 29).

A partir de las Ovoides gaditanas se desarrollarían en época tempranoaugustea (cf. alfar de Cerro de los Mártires-Gallineras, en San Fernando, García Vargas 1998: fig. 3: .3 y 42: 4) tanto las Dressel 9 como las Dressel 10. Muy pronto, las Dressel $10 \mathrm{C}$, herederas directas de las Ovoides, derivarán hacia las Dressel 9, por un lado, y las Dressel 10B, por otro. Las Dressel 9 conservarán de ellas el cuello y las asas cortos, así como los pivotes poco desarrollados, pero tenderán hacia cuerpos cilíndricos de hombros marcados o más anchos en el tercio inferior; las Dressel 10 mantendrán la regularidad ovoide del cuerpo de sus predecesoras, desarrollando en longitud los pivotes, el cuello y las asas, pero conservando en éstas últimas y hasta el final de su producción el característico perfil de codo resaltado, como demuestran las producciones del cercano alfar de Rancho Perera-Salto al Cielo (García Jiménez et alii 

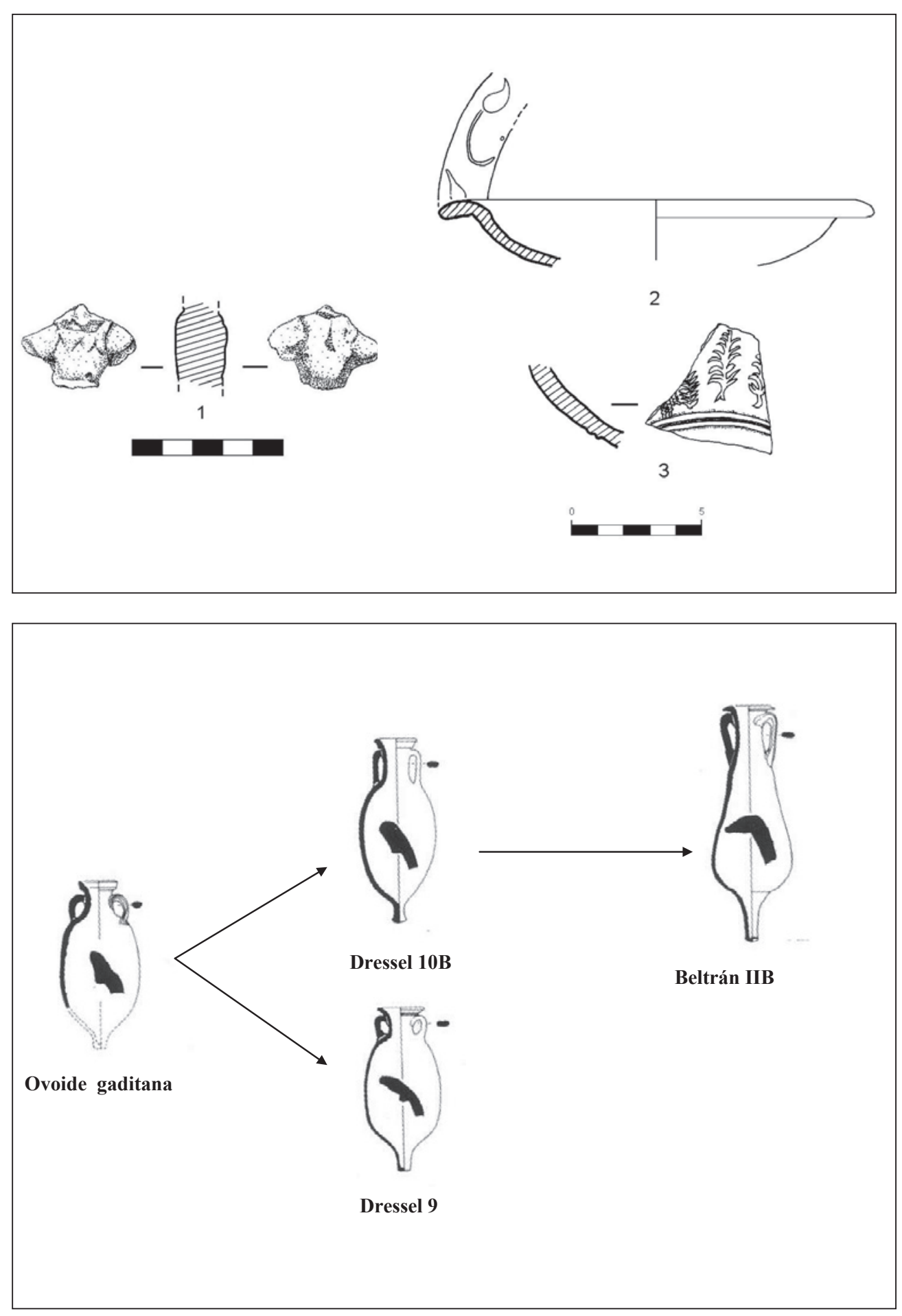

Figura 20 .

A: 1. Superficie: terracota figurativa;

2: material datante de la segunda fase de producción: TSG Drag. 35/36;

3: TSH: forma $37 \mathrm{~b}$.

B. Propuesta de evolución de las ánforas Ovoides a Beltrán II B. 
2004: fig. 2), también en la margen derecha del Guadalete correspondiente al término de Jerez de la Frontera (García Vargas 1998: 188, cf. "El Torno", Lagóstena Basrrio y Bernal Casasola 2004: 61, no 39) La estrecha relación morfológica entre todos estos contenedores se hace patente en la citada existencia de ejemplares que parecen responder a una morfología intermedia (Dressel 9/10) con ejemplares tanto en Rabatún, como en Jardín de Cano (López Rosendo 2008: figs. 7, 1-3) o Buenavista (Mata Almonte y Lagóstena Barrios 1997: Lám. 10,1), con cuerpo de tendencia tubular y asas cortas, redondeadas y con codo ligeramente resaltado. En tales casos, creemos, sin embargo, y a pesar de que conservamos la nomenclatura 9/10, que el escaso desarrollo del cuello, y, en especial, el índice anchura-altura del mismo, siempre inferior a 1,4 , permite considerarlas Dressel 9 mejor que Dressel 10.

Serán las producciones evolucionadas de Dressel 10B las que "desembocarán” en esta área de las campiñas septentrionales del Guadalete en la definición de un nuevo tipo: la Beltrán IIB, que pierde el perfil regular del cuerpo a favor de una morfología "piriforme" del mismo y suaviza las líneas de transición entre todas las secciones del recipiente (borde-cuello, cuellopanza; panza-pivote). Una confluencia entre las Dressel 10B y las Dressel 11 en la conformación del tipo Beltrán IIB es posible igualmente, a la vista de los ejemplares más antiguos de Beltrán IIB de la bahía (subtipo A) que conservan la moldura inferior del borde típica de las formas integrantes del grupo 7-11 de Dressel.

Si las producciones de Puerto real 1 son locales, y en cualquier caso las pastas parecen indicar que proceden de la campiña de Jerez, se haría igualmente patente la continuidad morfológica entre las Beltrán IIB y las Puerto Real 1, cuya zona de producción se alargaría entonces desde Puerto real a Jerez de la Frontera, pasando por la isla de San Fernando.

En resumen, del estudio de las formas anfóricas de Rabatún y el resto de los alfares excavados y publicados de las campiñas septentrionales del Guadalete se derivan dos consecuencias que creemos de interés morfo-cronológico:

1. La confirmación de una conexión y derivación tipológica entre las formas Ovoide gaditana, Dressel 9, Dressel 10B y C y Beltrán IIB (Fig. 17.B), con continuidad hasta el siglo III d. C. con el tipo Puerto Real 1.

2. La limitada presencia en el área, al menos en lo conocido hasta hoy, de los tipos Dressel 7 y 8, frecuentes desde época augustea al sur del Guadalete, en los alfares de San Fernando y Puerto Real. Tal vez pueda relacionarse esta ausencia con la también escasa representación de las Beltrán IIA en el marco de El Puerto-Jerez, lo que indicaría una eventual continuidad morfológica entre Dressel 7/8-Beltrán IIA, en cierto sentido paralela a la que existiría entre Dressel 9/10 y Beltrán IIB.

En cuanto a las cerámicas comunes, se observa una cierta "hibridación" formal entre las morfologías gadiritas tradicionales y las romano-itálicas en los tres alfares, pero especialmente en Rabatún, con un fuerte peso, no obstante, de la tradición alfarera romana que aflora en las jarras, en las ollas de borde horizontal o en las tazas (cf. también en Buenavista, Mata Almonte y Lagóstena Barrios 1997: lám. VI). En el fondo, este es el mismo fenómeno que se ha señalado para las ánforas romanas de la bahía de Cádiz (Martín-Kilcher 2001) que, una vez superada la fase de imitación de las morfologías romano-republicanas, cristalizan en un repertorio de indudable tradición itálica, el representado por las Dressel 7-11, en el que detalles como los pivotes huecos o las bocas fuertemente molduradas remiten a formas de hacer del artesanado tardopúnico que se habrían mantenido "fosilizadas" en la nueva tradición artesanal romano-gaditana.

No carece de interés retomar aquí, para finalizar, el debate acerca del contenido de estas series anfóricas de las campiñas septentrionales del Guadalete. Desde hace décadas, tanto los residuos del producto envasado documentados en ánforas Ovoides, Dressel 9, 10 y Beltrán II B de procedencia submarina (Chic García 1978), como el testimonio de los tituli picti, la mayoría igualmente de origen submarino, conservados en estas mismas formas (Liou 1988) han hecho pensar en un carácter bi- o polivalente para estas mismas tipologías que incluiría como producto relativamente habitual el vino y sus derivados (lora, lympha), así como otros jarabes o arropes (defrutum, sapa) derivados de la cocción del mosto, pero sin contenido alcohólico (García Vargas 1998: 206).

El hallazgo en el citado pecio Sud Perduto 2 (Bernard 2008: 462-463) de ánforas Dressel 9/10 y Dressel 10, muy similares morfológicamente a las series de Rabatún, con pepitas de uva en su interior, junto a Dressel 7 que contenían restos del esqueleto óseo de caballas, viene a confirmar el papel representado en el comercio del vino y sus derivados por algunas series de ánforas ovoides del grupo de las Dressel 9-10, a lo que habría que añadir las Beltrán II B con letreros que indican vino (Liou 1987), lo que refuerza la idea de una continuidad funcional entre ambas morfologías.

Tal vez sería demasiado simple, sin embargo, relacionar Dressel 7-8 con salazones y las inmediaciones de la bahía de Cádiz y Dressel 9-10 con vino y las campiñas septentrionales del Guadalete. Primero, porque 
la paleotopografía del entorno de Jerez indica la proximidad de Rabatún a la orilla del mar y sus esteros en época romana, y, luego, porque no faltan Dressel 9 y 10 fabricadas en San Fernando, Puerto Real y Chiclana; es decir que el panorama geográfico-tipológico del entorno de Cádiz-Jerez es más complejo de lo que estamos en condiciones por ahora de entrever. Pero no es menos cierto que lo que vamos sabiendo de estos alfares del norte del El Puerto y de Jerez justifica una revalorización de la importancia de la producción y la exportación del vino gaditano.

Lo mismo pasa con el aceite. Cuando en 1998, uno de nosotros publicó un ánfora olearia completa de la Plaza de San Antonio de Cádiz como Brindisina (García Vargas 1998: fig. 67.1), fue porque no se conocía la adscripción de estas tipologías al área de la campiña jerezana, cuyas pastas son ligeramente diferentes a las "clásicas" de la bahía gaditana. Hoy podemos incluir este ejemplar entre las Oberaden 83 de producción gaditana, como las de Rabatún, y añadir, por tanto, el aceite a las mercancías procesadas y envasadas en ánforas del entorno de la bahía de Cádiz.

Las consecuencias de este carácter diversificado de las producciones anfóricas gaditanas no son baladíes, debido a su enorme difusión "internacional", para los estudios sobre la economía "comercial" durante el Alto Imperio Romano, pero escapan a los modestos objetivos de este trabajo.

\section{BIBLIOGRAFÍA}

ALMEIDA, R. DE (2008): Las ánforas del Guadalquivir en Scallabis (Santarém, Portugal. Una aportación al conocimiento de los tipos minoritarios, Col. leccio Instrumenta 28. Barcelona.

BELTRÁN LLORIS, M. (1970): Las ánforas romanas en España., Zaragoza.

BERNAL CASASOLA, D. (1993): "Las terracotas del Rinconcillo (Algeciras-Cádiz): Una posible producción local de figurillas en época romana", $\mathrm{Al}$ moraima 9: 147.

BERNAL CASASOLA, D. y LAGÓSTENA BARRIOS, L. (2004): Figlinae Baeticae : talleres alfareros y producciones cerámicas en la Bética romana (ss. II a.C.-VII d.C.). Actas del Congreso Internacional (Cádiz, 12-14 de noviembre de 2003), BAR Int. Ser. 1266. Oxford.

BLÁNQUEZ PÉREZ, J.; PRADOS MARTÍNEZ, F.; ROLDÁN GÓMEZ, L. y BERNAL CASASOLA, D. (2004): "Villa Victoria y el barrio alfarero de Carteia en el s. I d.C.: avance de la excavación del 2003”, en D.
Bernal Casasola y L. Lagóstena Barrios (eds.), Figlinae Baeticae: talleres alfareros y producciones cerámicas en la Bética romana (ss. II a.C.-VII d.C.). Actas del Congreso Internacional (Cádiz, 12-14 de noviembre de 2003), BAR Int. Ser. 1266: 457-472. Oxford.

BERNARD, H. (2008): "Nouvelles épaves hispaniques de Corse. Sud Perduto 2 (Bonifacio) et Marina di Fiori (Porto Vecchio)", en J. Pérez Ballester y G. Pascual Berlanga (eds.), Comercio, redistribución y fondeaderos. La navegación a vela en el Mediterráneo. V Jornadas Internacionales de Arqueología Submarina: 461-471, Valencia.

CHIC GARCÍA, G. (1978): “Acerca de un ánfora con pepitas de uva encontrada en la Punta del Nao (Cádiz)", Boletín del Museo de Cádiz I: 37-42.

COLL CONESA, J. (2008): "Hornos romanos en España. Aspectos de morfología y tecnología", en D. Bernal Casasola y A. Ribera Lacomba (eds.), Cerámicas hispanorromanas. Un estado de la cuestión: 113-122. Cádiz.

CUOMO DI CAPRIO, N. (2007): Ceramica in Archeologia 2. Antiche tecniche di lavorazione e moderni metodi di indagine. Roma.

GARCÍA JIMÉNEZ, I.; ZULETA ALEJANDRO, F. y PRIETO REINA, O. (2004): "El yacimiento romano de El Torno-Cementerio de San Isidro del Guadalete", en D. Bernal Casasola y L. Lagóstena Barrios (eds.), Figlinae Baeticae: talleres alfareros y producciones cerámicas en la Bética romana (ss. II a.C.-VII d.C.). Actas del Congreso Internacional (Cádiz, 12-14 de noviembre de 2003), BAR Int. Ser. 1266: 663-666. Oxford.

GARCÍA VARGAS, E. (1996): “La Producción anfórica en la Bahía de Cádiz durante la República como índice de romanización", Habis 27: 49-62.

GARCÍA VARGAS, E. (1998): La producción de ánforas en la bahía de Cádiz en época romana (siglos II a.C. - $I V$ d.C.).Écija.

GARCÍA VARGAS, E. (2001): "La producción de ánforas romanas en el sur de Hispania. República y Alto Imperio", Ex Baetica Amphorae. Conservas, aceite y vino de la Bética en el Imperio Romano. Actas del Congreso Internacional. Sevilla-Écija, 17 a 20 de diciembre de 1998, vol. I: 57-174. Écija.

GARCÍA VARGAS, E. y LAVADO FLORIDO, M.L. (1995): “Ánforas alto, medio y bajoimperiales producidas en el alfar de Puente Melchor (=Villanueva Paso a Nivel, Puerto Real, Cádiz)", Spal 4: 215228. http://dx.doi.org/10.12795/spal.1995.i4.08

GARCÍA VARGAS, E. y LAVADO FLORIDO, M.L. (1996): "Definición de dos nuevos tipos de ánforas 
gaditanas: las Puerto Real 1 y 2", Spal 5: 197-208. http://dx.doi.org/10.12795/spal.1996.i5.10

GONZÁLEZ RODRÍGUEZ, R.; AGUILAR MOYA, L.; MARTÍN MOCHALES, D.; BARRIONUEVO CONTRERAS, F. y COLLADO MORENO, M. (2008): Carta Arqueológica Municipal de Jerez. 1: El núcleo urbano. Serie Monografías de Arqueología. Junta de Andalucía. Sevilla.

LAGÓSTENA BARRIOS, L. (1993-94): “Alfarería romana en la bahía de Cádiz. La producción anfórica", Boletín del Museo de Cádiz VI: 107-16.

LAGÓSTENA BARRIOS, L. (1996): Alfarería romana en la Bahía de Cádiz. Cádiz.

LAGÓSTENA BARRIOS, L. y BERNAL CASASOLA, D. (2004): "Alfares y producciones cerámicas en la provincia de Cádiz. Balance y perspectivas", en D. Bernal Casasola y L. Lagóstena Barrios (eds.), Figlinae Baeticae: talleres alfareros y producciones cerámicas en la Bética romana (ss. II a.C.-VII d.C.). Actas del Congreso Internacional (Cádiz, 12-14 de noviembre de 2003), BAR Int. Ser. 1266: 39-124. Oxford.

LEIBUNDGUT, A. (1977): Die Römischen lampen in der schweiz: Eine Kultur-und handelsgeschichtliche studie. Berna.

LIOU, B. (1987): "Inscriptions peintes sur amphores: Fos (suite), Marseille, Toulon, Port-la-Nautique, Arles, Saint Blaise, Saint-Martin-de-Crau, Mâcon, Calvi", Archaeonautica 7: 55-139.

LIOU, B. (1988): "Le contenu des amphores: typologie et epigrafie: quelques cas aberrants ou embarrasants", S.F.E.C.A.G. Actes du Congrès de Orange: 171-77.

LÓPEZ MULLOR, A. (2008): "La cerámica de paredes finas en la fachada mediterránea de la Península Ibérica y las Islas Baleares", en D. Bernal Casasola, D. y Ribera Lacomba, A. (eds.), Cerámicas hispanorromanas. Un estado de la cuestión: 343-382. Cádiz.

LÓPEZ ROSENDO, E. (2007): "El yacimiento arqueológico de Los Villares/Montealto y los orígenes tartésicos y romanos de la población de Jerez", Revista de Historia de Jerez 13: 9-34.

LÓPEZ ROSENDO, E. (2008): "El alfar romano altoimperial del Jardín de Cano", Revista de Historia de El Puerto 41: 39-74.

LÓPEZ ROSENDO, E. (2009): "Intervención arqueológica urgente en el yacimiento de Los Villares de Jerez de la Frontera (Cádiz). Campaña de 2004", en Anuario Arqueológico de Andalucía 2004 III, tomo 1: 369-378.
LÓPEZ ROSENDO, E. (e.p.a): "El yacimiento tartésico y romano de Los Villares/Rabatún, al Noroeste de la ciudad de Jerez de la Frontera (Cádiz). Intervención arqueológica preventiva de 2004/2005", en Anuario Arqueológico de Andalucía 2005, tomo II. Actividades Preventivas. Consejería de Cultura de la Junta de Andalucía. Sevilla.

LÓPEZ ROSENDO, E. (e.p.b): "Los talleres alfareros del Jardín de Cano (El Puerto de Santa María, Cádiz): la producción cerámica de Gades en torno al cambio de era", Rei Cretariae Fautores, $26^{\text {th }}$ Internacional Congreso, Cádiz 2008.

MARTIN KILCHER, S. (2001): “Amphores à sauces de poisson du sud de la péninsule ibérique dans les provinces septentrionales", Ex Baetica Amphorae. Conservas, aceite y vino de la Bética en el Imperio Romano. Actas del Congreso Internacional. Sevilla-Écija, 17 a 20 de diciembre de 1998, vol. III: 759-786. Écija.

MATA ALMONTE, E. y LAGÓSTENA BARRIOS, L. (1997): "Ocupación antigua en la Sierra de San Cristóbal (El Puerto de Santa María, Cádiz)", Revista de Historia de El Puerto 18: 11-45.

MORAIS, R. (2004): "Problematiques i noves perspectives sobre les ámfores ovoides tardo-republicaines. Les àmfores ovoides de producció lusitana", en C. Carreras Monfort y X. Aquilué (eds.), Culip VIII i les àmfores Haltern 70. Museu d'Arqueologia de Catalunya, Centre d'Arqueologia Subaquàtica: 36-40. Gerona.

PUIG, A. (2004): "Evolució de les Haltern 70", C. Carreras Monfort y X. Aquilué (eds.), Culip VIII i les àmfores Haltern 70. Museu d'Arqueologia de Catalunya, Centre d'Arqueologia Subaquàtica: 23-32. Gerona.

RAMOS, Ma. L. (2008): "Terracotas y elementos de coroplastia", en D. Bernal Casasola y D. Ribera Lacomba, A. (eds.), Cerámicas hispanorromanas. Un estado de la cuestión: 775-785. Cádiz.

SÁEZ ROMERO, A. (2005): "Aproximación a la tipología de la cerámica común púnico-gadirita de los ss. III-II", Spal 14: 145-178. http://dx.doi.org/10.12795/ spal.2005.i14.06

SÁEZ ROMERO, A. M., y SÁEZ ESPLIGARES, A., (2004): "Control arqueológico de urgencia realizado en el solar ubicado en C/ Albardonero 24 (San Fernando, Cádiz)", Anuario Arqueológico de Andalucía 2001, vol. III: 93-98. Sevilla.

VAQUERIZO GIL, D. (2004): Inmaturi et inupti, Col. lecció Instrumenta, $\mathrm{n}^{\circ} 15$. Barcelona. 